\title{
Desigualdade de Rendimentos do Trabalho no Curto e no Longo Prazo: Tendências de Idade, Período e Coorte*
}

\author{
Rogério Jerônimo Barbosa
}

Universidade de São Paulo (USP), São Paulo, SP, Brasil. E-mail: antrologos@gmail.com

\section{INTRODUÇÃO}

\begin{abstract}
A nálises da desigualdade de rendimentos do trabalho usualmente sugerem que os índices respondem basicamente a políticas públicas e fatores conjunturais. No entanto, a variação ou a estabilidade de qualquer fenômeno sempre contém em si processos de temporalidades distintas - alguns deles gestados durante décadas a fio e que atuam de modo quase invisível. O objetivo deste artigo éjustamente separar e diferenciar esses vetores de curto e longo prazo. Considero que as tendências podem ser decompostas em três categorias: idade, período e coorte (IPC).
\end{abstract}

Rendimentos estão ligados ao ciclo de vida: há expectativas sociais sobre a idade para começar a trabalhar, estudar, se casar, se aposentar etc. Indivíduos com diferentes idades encaram oportunidades e barreiras específicas. O envelhecimento é o caminho entre a origem e o destino, na estratificação social (Blau e Duncan, 1967; Hasenbalg e Silva, 2003); deste modo, a diversidade de percursos trilhados pode acarretar redu-

\footnotetext{
* Agradeço os comentários e a cuidadosa leitura de Marcelo Medeiros, Pedro G. H. F. Souza, Marta Arretche, André Portela, Flávio Carvalhaes, Carlos Antônio Costa Ribeiro, Ian Prates e Nadya A. Guimarães. O desenvolvimento deste artigo contou com o financiamento do Conselho Nacional de Desenvolvimento Científico e Tecnológico (CNPq) (bolsa de doutorado) e do Centro de Estudos da Metrópole (Cepid/Fapesp).
}

DADOS - Revista de Ciências Sociais, Rio de Janeiro, vol. 59, n² 2, 2016, pp. 385 a 425. 
ção ou ampliação das desigualdades iniciais. Chamarei esses aspectos de efeitos de idade.

Por outro lado, a distribuição de rendimentos também responde a eventos de curto prazo, conjunturas macroeconômicas ou políticas. São exemplos: inflação, crise e crescimento econômico, programas sociais. Fenômenos desse tipo afetam a todos ao mesmo tempo, independentemente da idade ou geração a que pertencem. São efeitos de período.

Por fim, uma sociedade está em permanente reposição: novas gerações substituem as precedentes - e cada experiência geracional ocorre sob condições distintas. Tomemos dois exemplos. A geração de 1915 iniciava a vida econômica quando estoura a crise de 1929. É provável que tenha carregado uma "marca geracional" desfavorável por todo seu percurso. Por contraste, os baby boomers (nascidos entre 1945 e 1960) tinham a idade certa no momento certo para se apropriar de diversos benefícios econômicos (Chauvel e Schröder, 2014). Tais "marcas geracionais" são efeitos de coorte (cf. Ryder, 1965).

A qualquer momento, haverá coexistência de processos ligados a essas três temporalidades. Porém, efeitos de idade e coorte acumulam-se e se fazem sentir apenas no longo prazo e não são prontamente distinguíveis em análises descritivas. No Brasil, quase a totalidade dos estudos sobre desigualdade voltou-se apenas para os "determinantes imediatos" (Barros, Foguel e Ulyssea, 2006). Somente Firpo, Gonzaga e Narita (2003) tentaram realizar uma decomposição segundo essas dimensões ${ }^{1}$. São várias as razões para a escassez desse tipo de abordagem. Primeiramente, para as políticas públicas, interessa saber principalmente os efeitos imediatos de suas intervenções. Em segundo lugar, há grandes dificuldades metodológicas para separar esses efeitos.

Neste artigo, analiso a distribuição dos rendimentos do trabalho para os indivíduos com idades entre 25 e 65 anos, observados no período de 1981 a 2013 (coortes de 1916 a 1988). Faço análises separadas para homens e mulheres, pois o padrão e os mecanismos do mercado variam enormemente por sexo ${ }^{2}$. De saída, a inserção dos homens na PEA (População Economicamente Ativa) permaneceu estável durante todo o período considerado (Rios-Neto e Oliveira, 1999; Oliveira e Rios-Neto, 2004); ao passo que, entre as mulheres, os padrões de atividade alteraram-se intensamente (Guimarães, Barone e Brito, 2015). A pergunta norteadora é: em que medida o movimento das desigualdades de rendimento do trabalho responde a processos de longo prazo? Com isso, 
obviamente, refiro-me às características geracionais e às alterações na estrutura etária. Recuperar o longo prazo é também remeter aos propósitos iniciais das análises sobre desigualdade, que pensavam nas transformações e processos macrossociais e econômicos.

Vale sublinhar que este estudo se dedica à compreensão da desigualdade de rendimentos apenas do trabalho e somente "abaixo do topo". Em artigos recentes, Medeiros e Souza (Medeiros, Souza e Castro, 2014a, 2014b; Souza e Medeiros, 2015; Souza, 2014) mostraram que surveys domiciliares sub-representam e captam mal as informações de renda dos mais ricos. Incluindo o "topo", os índices de desigualdade apresentam estabilidade, ao invés de queda. O caráter recente desses achados ainda não possibilitou que todas as suas consequências tenham sido avaliadas. Uma leitura apressada poderia sugerir que a estabilidade dos indicadores na "distribuição completa" da renda (isto é, incluindo os ricos) implicaria até mesmo estabilidade de outros aspectos sociais desiguais. Contudo, Souza e Medeiros (2015) indicam que os ganhos da base foram contrabalanceados pelo aumento da concentração no topo, gerando um jogo de soma zero. Argumento que a conhecida trajetória de declínio da desigualdade, conforme medida por survey, representa real mudança nas capacidades de extrair ganhos do mercado para os mais pobres e para a classe média - ainda que, eventualmente, os eixos mais fundamentais da distribuição de poder tenham se mantido inalterados. A estabilidade dos indicadores globais de desigualdade não implica completa ausência de redistribuição.

O principal achado deste artigo é que, para os homens, a queda das desigualdades empiricamente observada na base e no meio da distribuição de renda é principalmente fruto de um processo de longo prazo, e coincide com a homogeneização educacional das coortes - possivelmente respondendo à modernização da economia. Aparentemente, os efeitos de curto prazo das conjunturas econômicas favoráveis e medidas políticas tomadas a partir do final dos anos 1990 apenas conseguiram mitigar as consequências trazidas pelas crises e instabilidades dos anos 1980. Para as mulheres, o diagnóstico é bastante diverso. A desigualdade da renda do trabalho entre coortes permaneceu estável e não esteve associada à igualdade de oportunidades educacionais. A queda dos indicadores se deve sobretudo a efeitos de período, intensificados a partir de 1993-1994. Ou seja, trata-se de um processo mais recente e que favoreceu mulheres de todas as coortes e idades ao mesmo tempo. 
O artigo é composto de sete seções, fora esta Introdução. A seção seguinte revisa explicações sobre as desigualdades de renda no Brasil. $\mathrm{Na}$ terceira, apresento alguns dados descritivos. Na quarta, aponto as principais abordagens sobre IPC. Nas seções seguintes, formalizo os modelos que serão submetidos a teste. Em seguida, apresento os resultados e faço algumas considerações finais.

\section{ABORDAGENS SOBRE AS DESIGUALDADES DE RENDIMENTOS DO TRABALHO NO BRASIL}

O debate sobre as desigualdades de rendimentos no Brasil iniciou-se nos anos 1970, quando microdados dos Censos de 1960 e 1970 tornaram-se disponíveis e informaram trabalhos pioneiros. Naquele contexto, inaugurou-se a famosa "controvérsia dos anos 1970" sobre a concentração de renda durante o milagre econômico (Hoffmann e Duarte, 1972; Fishlow, 1972; Langoni, 1973).

Para Fishlow (1972), o crescimento da desigualdade durante a década de 1960 esteve relacionado com mecanismos de compressão salarial vigentes na Ditadura Militar (1964-1984). Em especial, a desvalorização do salário mínimo, a elevada inflação (que fizeram com que os índices de correção dos salários estivessem defasados), a implementação de poupança compulsória e a desmobilização dos mecanismos de barganha.

Contra Fishlow, Langoni (1973) lançou mão da Teoria do Capital Humano e enfatizou a importância das mudanças tecnológicas e do aumento da demanda por qualificação. Langoni argumentou que os raros indivíduos com maior escolarização acabaram por receber retornos desproporcionalmente elevados devido à alta demanda num contexto de oferta inelástica. Gerou-se um grande prêmio salarial, que a princípio seria temporário (quasi-rent), um "Efeito Kuznets". A economia se modernizava e não era possível qualificar a mão de obra na mesma velocidade.

Estava em jogo uma disputa entre fatores explicativos econômicos e não econômicos. Malan e Wells (1973) criticavam justamente a ausência da dimensão institucional no trabalho de Langoni - apontando que seu diagnóstico de que os desequilíbrios de mercado teriam fim no longo prazo seria um "ato de fé". Trabalhos posteriores, como os de Bacha (1978a, 1978b) e Bacha e Taylor (1980), enfatizaram outras fontes de explicação, como o desenho institucional das firmas e a proximidade en- 
tre os interesses de proprietários e gerentes. Toda essa literatura tinha como foco explicar processos de longo prazo ligados ao desenvolvimento econômico e à modernização da sociedade.

Aspectos políticos e não produtivos sempre foram contrapostos à teoria neoclássica. Mas, após os anos 1960 e 1970, o foco nas dinâmicas de mercado (na "corrida" entre qualificação e tecnologia - cf. Goldin e Katz, 2009) parece ter suplantado as outras perspectivas na Economia mainstream. A literatura mais recente sobre desigualdades no Brasil (anos 1990 e 2000) se estabeleceu sobre um modelo neoclássico (cf. Gandra, 2005), no qual a educação e a remuneração pela produtividade marginal assumem preeminência. O extenso rol de estudos que se seguiu especializou-se em medir o movimento dos indicadores no curto prazo.

Em todo esse contexto, os sociólogos mantiveram-se relativamente distantes do estudo dos determinantes e da distribuição dos rendimentos - não apenas no Brasil, como atestam Morris e Western (1999) e DiPrete (2007). Olhando para a produção americana, DiPrete acredita que, dentre as diversas razões para o distanciamento com respeito a esse tema, figuram o foco privilegiado dirigido às desigualdades ocupacionais e a relativa falta de interesse nas instituições do mercado de trabalho. No contexto brasileiro, ao menos na Estratificação Social, os sociólogos se comportaram de modo a mimetizar a literatura internacional; deixando de lado o estudo da renda (com poucas exceções, como Silva, 2003) e se comunicando pouco com os estudos sobre o mercado de trabalho (cf. Guimarães, Barbosa e Carvalhaes, 2012).

Alguns trabalhos recentes têm mostrado formas pelas quais é possível dar uma contribuição sociológica: levando em consideração de modo mais consequente as instituições (Morris e Western, 1999; DiPrete, 2007); a estrutura ocupacional (Mouw e Kalleberg, 2010; Carvalhaes et al., 2014; Carvalhaes e Souza, 2014; Barbosa e Prates, 2015); e as políticas públicas (McCall e Percheski, 2010). Em todos esses estudos, no entanto, ainda é ausente um olhar para o longo prazo - característico dos debates iniciais. Argumento que identificar marcas das coortes é uma forma de rastrear as consequências que o desenvolvimento econômico podem ter acarretado sobre a distribuição de renda. Além disso, ampliar o enfoque temporal é reconhecer que a realidade observada em determinado ponto não advém apenas do imediato, e que partes distintas de estrutura das desigualdades respondem em velocidades próprias. 


\section{TENDÊNCIAS EMPÍRICAS DAS DESIGUALDADES}

No Brasil, a narrativa mais conhecida é aquela que se constrói a partir de dados $^{3}$ como os do Gráfico 1 . Os índices cresceram durante a década de 1980, correlacionados às crises econômicas e com pico em 1989. A literatura dirigiu grande atenção à inflação, às políticas monetárias e à variação do Produto Interno Bruto (PIB). Durante a década de 1990, a volatilidade econômica se reduz, mas os indicadores tornam-se estacionários em torno de um patamar elevado. A preocupação dos especialistas se voltou para a explicação dessa "estabilidade inaceitável" (Barros et al., 2006). No fim dos anos 1990 já se observa uma leve queda na desigualdade da renda do trabalho (cf. idem). Apenas depois de 2005 os índices começaram a cair visivelmente (Ferreira et al., 2006). Entre os economistas, a expansão educacional passa a ser diagnosticada como o principal determinante da equalização salarial (Barros et al., 2006).

Não é possível dizer que essas conhecidas tendências estejam relacionadas apenas às decisões tomadas em cada contexto. Nos períodos recentes, há predominância de coortes mais jovens e, nos mais antigos, das coortes mais velhas - a substituição geracional pode ter contribuído na produção desses resultados. Assim, diferentemente do que sugere à primeira vista, o Gráfico 1 não expressa somente os efeitos de período.

Dois outros gráficos são complementares ao primeiro. O Gráfico $2 \mathrm{~A}$ traz o Theil-L calculado para cada idade, entre 25 e 65 anos, e o Gráfico 2B para cada coorte de nascimento de 1916 a 1988. Ambos se baseiam no empilhamento dos bancos de dados anuais.

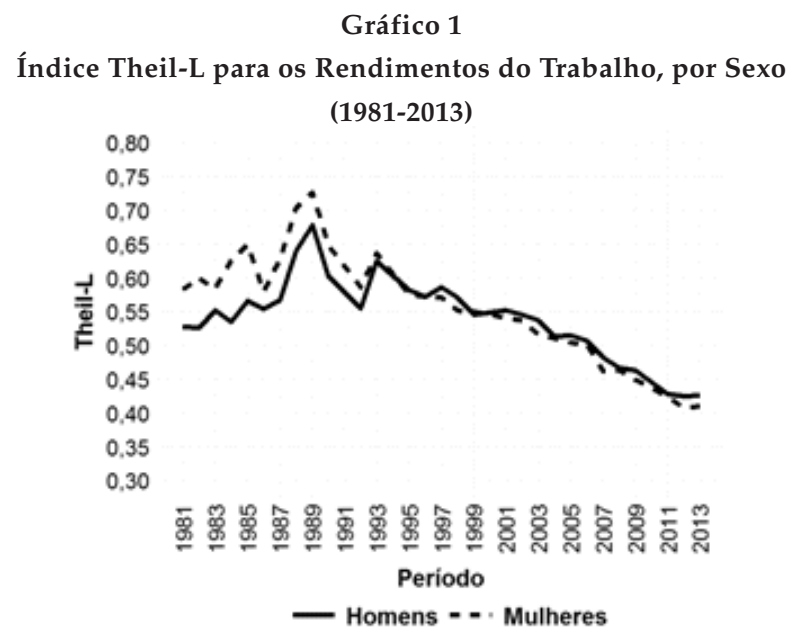

Fonte: PNADs 1981-2013; elaboração própria. 
Desigualdade de Rendimentos do Trabalho no Curto e no Longo Prazo...

Gráfico 2

Desigualdades de Rendimentos do Trabalho (Theil-L) por Idade e Coorte

Gráfico $2 \mathrm{~A}$

Idade ( 25 a 65 anos)

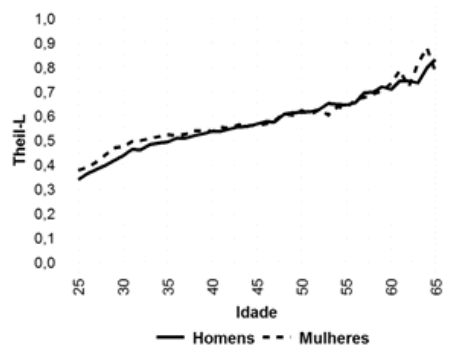

Gráfico 2B

Coorte (1916-1988)

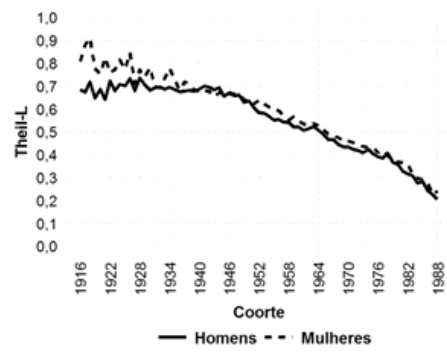

Fonte: PNADs 1981-2013; elaboração própria.

O Gráfico 2A indica que há mais desigualdade nas idades avançadas. No entanto, ainda não podemos dizer que esses são, de fato, os efeitos do envelhecimento e do curso de vida. Indivíduos mais velhos são majoritariamente de coortes antigas e os jovens, de coortes recentes. Ao invés de expressar o "curso de vida médio", esse gráfico pode estar distorcido por efeitos de coorte e período. O mesmo é verdade para o Gráfico 2B: a coorte nascida, por exemplo, em 1916, apenas foi observada uma única vez, em 1981, já com 65 anos de idade. Não sabemos se a informação sobre esses indivíduos reflete mais o efeito do envelhecimento ou uma característica geracional. Se há desigualdades cumulativas no ciclo de vida, então a elevada disparidade salarial das coortes antigas pode estar relacionada ao fato de que as observamos quando mais velhas. Há duas dificuldades intrínsecas à análise IPC: qualquer análise descritiva traz uma mistura de efeitos e há desbalanceamento no número de casos em pelo menos uma das dimensões.

No Quadro 1A, de idades por períodos, as coortes figuram na diagonal. Neste exemplo, a coorte 7 foi observada com 4 anos de idade no Período 1, com 5 anos de idade no período 2 etc. Num quadro de coortes por períodos como o 1B, as idades ficam na diagonal. As informações das diagonais são sempre desbalanceadas. Na análise realizada aqui, optei por partir de um quadro de idades por períodos. Assim, o número de coortes está desbalanceado. Nesse caso, quando há um número $i$ de idades e um número $j$ de períodos, haverá $i+j-1$ coortes. Considerando apenas os anos em que a Pesquisa Nacional por Amostra de Domicílios (PNAD) foi realizada, tenho 33 períodos, 41 grupos etários 
Quadro 1

Quadro 1A

Idade $x$ Período (coorte na diagonal)

\begin{tabular}{|c|c|c|c|c|}
\hline & Período 1 & Período 2 & Período 3 & Período 4 \\
\hline Idade 4 & Coorte 7 & & & Coorte 10 \\
\hline Idade 5 & & Coorte 7 & & \\
\hline Idade 6 & & & Coorte 7 & \\
\hline Idade 7 & Coorte 4 & & & Coorte 7 \\
\hline Idade 8 & & Coorte 4 & & \\
\hline Idade 9 & & & Coorte 4 & \\
\hline Idade 10 & Coorte 1 & & & Coorte 4 \\
\hline
\end{tabular}

Quadro 1B

Coorte $x$ Período (idade na diagonal)

\begin{tabular}{|c|c|c|c|c|}
\hline & Período 1 & Período 2 & Período 3 & Período \\
\hline Coorte 1 & Idade 10 & & & Idade 13 \\
\hline Coorte 2 & & Idade 10 & & \\
\hline Coorte 3 & & & Idade 10 & \\
\hline Coorte 4 & Idade 7 & & & Idade 10 \\
\hline Coorte 5 & & Idade 7 & & \\
\hline Coorte 6 & & & Idade 7 & \\
\hline Coorte 7 & Idade 4 & & & Idade 7 \\
\hline Coorte 8 & & Idade 4 & & \\
\hline Coorte 9 & & & Idade 4 & \\
\hline
\end{tabular}

(idades de 25 a 65 anos) e 73 coortes. Na seção seguinte apresento as discussões metodológicas sobre o tema.

\section{O PROBLEMA DE IDENTIFICAÇÃO E OS MODELOS IPC}

Primeiramente, deve-se notar a igualdade matemática entre os três termos:

$$
P=I+C
$$

Período é igual idade mais coorte (i.e., o ano corrente é a soma de sua idade e o ano em que você nasceu). A posse de duas informações permite conhecer a terceira. Esse fato tem grandes consequências. Para ilustrá-las, tomo de empréstimo um exemplo de Bell e Jones (2013): suponhamos que um fenômeno qualquer $(Y)$ seja determinado por efeitos de idade, período e coorte, como numa equação de regressão. Nessa ilustração, a magnitude de todos os efeitos (coeficientes) será igual a um:

$$
Y=P+I+C
$$

Para saber o valor de Y para um indivíduo vivendo em 2013, com 25 anos (i.e., nascido em 1988), informamos esses valores na equação: $P+I+C=2013+25+1988=4.026$. No entanto, substituindo a Equação (1) em (2), obtemos:

$$
Y=2 I+2 C
$$

Chegamos à conclusão de que $\mathrm{Y}$ é determinado apenas por idade e coorte - não há efeito de período. Mas podemos usar a Equação (1) de novo. Substituindo-a em (3) obtemos: 
$\mathrm{Na}$ Equação (4), há apenas período. Observe que todas as equações produzem os mesmos valores preditos para Y. Mas qual está "correta"? Cada uma permite explicações diferentes: a) determinação simultânea pelos três componentes; $b$ ) prevalência de efeitos de longo prazo (idade e coorte) e c) existência apenas de efeitos conjunturais (período). São conclusões contraditórias. OQuadro 1 implica que não é possível inserir as três variáveis ao mesmo tempo num modelo de regressão ${ }^{4}$.

A igualdade expressa na Equação (1) indica que, se passarmos de um período a outro, todas as coortes envelhecerão simultaneamente. Não é possível fazer com que apenas a idade varie, mantendo período e coorte fixos. Esse quadro tornou-se conhecido como o problema de identificação dos modelos de IPC. Há dois tipos de estratégias para lidar com esse impasse:

- A estimação de modelos com restrições nos quais se assume igualdade, ausência ou uma forma funcional específica para os efeitos.

- Uso de medidas diretas/proxies, no lugar de uma ou mais das três variáveis.

O modelo sem restrição seria aquele que descreve a relação entre as variáveis exatamente como a teoria estabelece. Neste exemplo, seria a Equação (2) que, no entanto, não é estimável. Modelos com restrição impõem limites à forma funcional (i.e., ao desenho que a linha de regressão pode assumir: reta, parábola etc.). Porém, desvios da forma "correta" que efetivamente geraram os dados podem acarretar vieses em todos os coeficientes e produzir resultados arbitrários (Luo, 2013a, 2013b, 2013c; Luo et al., 2014; Bell e Jones, 2013a, 2013b, 2014, 2015). O desafio é estabelecer uma restrição teoricamente justificada, estimável e que traga resultados confiáveis. Apresento, então algumas tentativas de solução desse impasse, das quais farei uso. Como todas as propostas trazem certo grau de arbitrariedade, é prudente lançar mão de mais de uma estratégia.

Mason et al. (1973) propõem um modelo usando variáveis dummy para as categorias de cada uma das três variáveis. Usualmente, num modelo de regressão com uma variável explicativa categórica com $m$ alternativas, criamos $m$ - 1 variáveis dummy e deixamos uma categoria como referência. Se não houvesse problema de identificação, idade, $\operatorname{com} j$ valores 
únicos, seria representada por $j-1$ dummies; período, com $k$ categorias, por $k-1$ dummies; coorte seria representada por $j+k-2$ dummies. Mason et al. (idem) sugerem a fusão de duas categorias de uma das dimensões IPC - por exemplo, fazer com que período seja representado por $k$ - 2 dummies. Isso equivale a assumir que os efeitos de dois períodos são idênticos. Com isso, a colinearidade perfeita se quebra. O problema é a impossibilidade de testar se essa restrição é, de fato, adequada. Quais seriam as duas categorias com efeitos idênticos, afinal? A aplicação de restrições deve ser amparada por informações externas (side information).

Deaton e Paxson (1993) estabelecem que, se compreendermos que as transformações sociais ocorrem apenas no longo prazo, os efeitos conjunturais podem ser tratados como choques com média zero. Nesses casos, assume-se que as tendências podem ser atribuídas aos efeitos de coorte e aplica-se uma restrição aos efeitos de período. Trata-se de um pressuposto muito forte, que pode não se aplicar a todos os casos. No Brasil, esse modelo foi utilizado por Firpo, Gonzaga e Narita (2003) e por Reis e Gonzaga (2006).

O segundo conjunto de soluções substitui as variáveis IPC por medidas diretas dos conceitos aos quais elas se referem. Compreende-se que idade, período e coorte não são fenômenos sociológicos, mas agregados de efeitos produzidos por diversos mecanismos. O "período" é um conjunto de características que podem ser compreendidas como conjuntura. Deste modo, ao invés de utilizar o ano como variável explicativa, podemos lançar mão de características como inflação, taxa de desemprego etc. Idade pode dizer respeito ao envelhecimento, ao ganho de experiência, à aquisição de credenciais. Marcas de coorte podem estar ligadas às políticas educacionais existentes durante a infância; ao fato de ter crescido durante uma recessão. Charles Manski (2003) afirma que problemas de identificação (i.e., de "estimabilidade" dos modelos) são problemas de lógica dedutiva, um sintoma matemático de uma dificuldade mais fundamental de teorizar sobre as causas. Críticos entendem que os modelos tradicionais IPC tentam resolver pela técnica o que, na realidade, é uma confusão do analista (Glenn, 1976; Rodgers, 1982a e 1982b; Heckman e Robb, 1985; Glenn, 1989a e 1989b; Fienberg, 2013; Bell e Jones, 2013a). Nesse sentido, o uso de medidas diretas é uma tentativa de avançar substantivamente o conhecimento do fenômeno. Farei uso de dois desses modelos. Um com medidas que tentam capturar efeitos de período e outro para coorte. Os detalhes serão discutidos adiante. 
É importante ressaltar ainda que, na década de 2000, as análises IPC ganharam novo fôlego e visibilidade. Fu (2000) e Yang, Fu e Land (2004) desenvolveram um modelo chamado Estimador Intrínseco (IE, intrinsic estimator). Esse nome advém do fato de que nenhuma restrição explícita é feita aos coeficientes. Por isso, esse grupo de autores inicialmente afirmou ter "solucionado o problema de identificação". Em trabalhos posteriores Yang e Land (2006, 2008 e 2013), apresentaram um modelo mais flexível e aplicável a microdados, denominado Hierarchical Age Period Cohort Model (HAPC). Do ponto de vista conceitual, pode-se pensar que idade é uma característica individual, enquanto coorte e período são aspectos macrossociais. Um indivíduo é "crossclassificado" em dois grupos, justificando a alcunha de hierárquico.

Recentemente, importantes críticas foram feitas a esses novos modelos. Liying Luo (Luo 2013a e 2013b; Luo et al., 2014) mostrou que o IE possui uma restrição implícita, que obedece meramente a critérios matemáticos que o analista não tem possibilidade de alterar. Exercícios com simulação mostraram que o IE não está inume a vieses e resultados arbitrários. Paralelamente, Luo (2013c) e Bell e Jones (2013b e 2014) mostram que também o HAPC é um estimador restrito e que está à mercê dos mesmos problemas.

Não há solução definitiva para o problema de identificação nas análises IPC. A estratégia empírica adotada aqui se baseia no uso de seis diferentes modelos, que partem de suposições distintas. Farei uso das duas classes: tanto aqueles com restrição como aqueles que utilizam medidas diretas. Dentre os modelos restritos, figuram aqui o de Mason et al. (1973); Deaton e Paxson (1993), o estimador intrínseco de Yang, Fu e Land (2004) e uma proposta de efeitos mistos baseada no HAPC. Com respeito aos modelos com medidas diretas - inspirados em Rodgers (1982a), Heckman e Robb (1985) e O'Brien (2000) -, um deles lança mão de variáveis que identificam as características de período, outro utiliza características das coortes. Os detalhes estão na seção Metodologia e no Apêndice.

\section{MEDIDAS DIRETAS}

Nesta seção, indico brevemente a pertinência das informações que compõem os dois modelos com medidas diretas. A princípio, todas as três dimensões (idade, período e coorte) poderiam ser substituídas por medidas diretas. No entanto, a substituição de pelo menos uma já 
Gráfico 3

Inflação Acumulada nos 12 Meses Anteriores à Aplicação da PNAD

(INPC/IBGE)

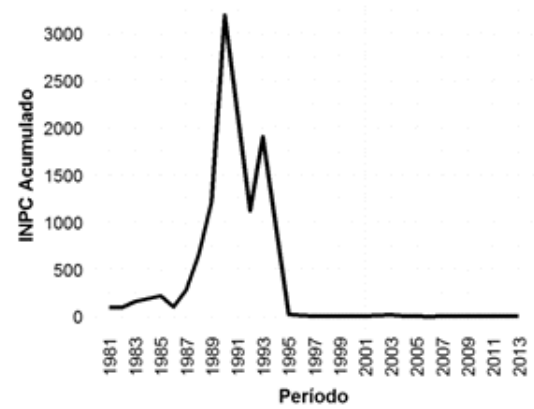

Gráfico 4

Log Natural da Inflação Acumulada nos

12 Meses Anteriores à Aplicação da

PNAD

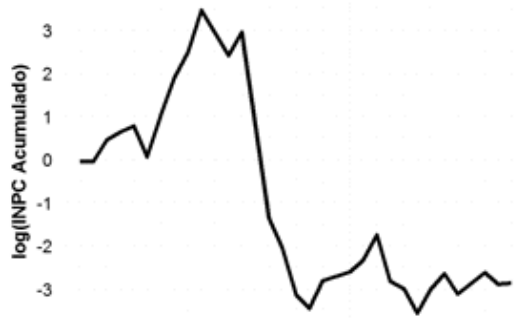

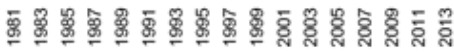

Periodo

Fonte: IpeaData.

garante identificação matemática e possibilidade de estimação. Os efeitos de período serão compreendidos como características cíclicas da economia (inflação e crescimento/crise) e ligadas à regulação política do mercado de trabalho (valor do salário mínimo e sua cobertura). São aspectos que afetam toda a população; ou seja, da forma como foram medidos, configuram-se como efeitos de período.

Há grande controvérsia sobre os determinantes das desigualdades. Por esta razão, apenas pretendo elencar variáveis correlacionadas com o fenômeno e que expressam as tendências de período de modo conceitualmente independente dos efeitos de coorte e vice-versa. As medidas de período podem ser até mesmo endógenas e isso não afetará os coeficientes estimados para idade e coorte - veja o Apêndice.

Há evidências que conectam a hiperinflação no Brasil no final dos anos 1980 e o levante da desigualdade (Cardoso, 1993; Cardoso, Barros e Urani, 1993; Neri, 1995; Hoffmann, 1998 e 2001; Ferreira et al., 2006), embora não seja consensual uma relação causal (cf. Barboza, 2008). Ferreira et al. (2006) sugerem que os salários são justamente a fonte mais afetada pela inflação. Como medida de inflação, utilizarei o logaritmo do Índice Nacional de Preços ao Consumidor (INPC) acumulado nos 12 meses que antecedem as PNADs.

O crescimento da economia, conforme medido pelo PIB per capita, é associado à distribuição de renda desde Kuznets (1955). Ainda que a 
Desigualdade de Rendimentos do Trabalho no Curto e no Longo Prazo...

Gráfico 5

PIB per capita, 1981-2013, Brasil

(em R\$ de 2012)

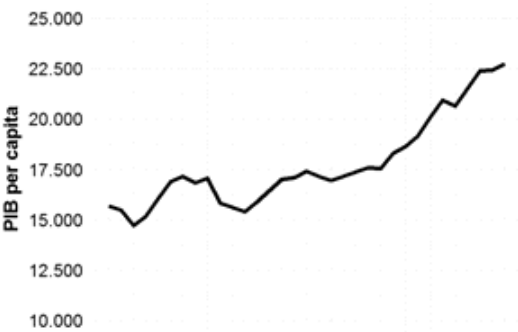

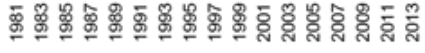

Periodo
Gráfico 6

Variação Real do PIB per capita, 1981-2013, Brasil (em \%)

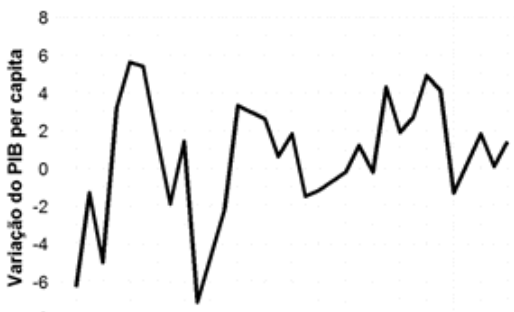

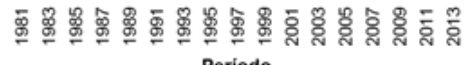

Fonte: Banco Central.

influência direta seja questionável, o crescimento está correlacionado à geração de empregos e aos salários. Durante as crises dos anos 1980, as desigualdades parecem variar quase com a mesma volatilidade que o PIB. A estagnação dos anos 1990 se fez acompanhar de uma tímida queda dos indicadores. O crescimento econômico dos anos 2000, por sua vez, foi simultâneo à desconcentração de renda (Carvalhaes et al., 2014). Utilizo tanto o nível do PIB per capita (em R $\$$ de 2012) como sua variação percentual.

Parece ser consensual que, no Brasil, oSM tem contribuído para a redução das desigualdades - diretamente, através do trabalho (Reis, 1989;

\section{Gráfico 7}

Valor do Salário Mínimo (SM) Real no

Período de Referência das PNADs,

1981-2013, Brasil (em R\$ de 10/2014)

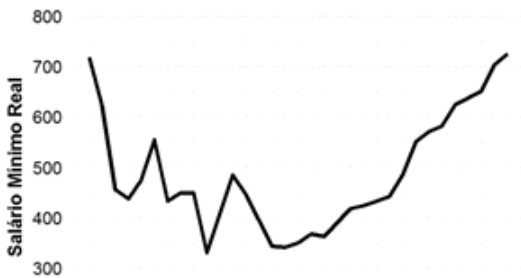

200

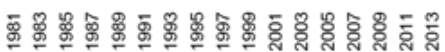

Gráfico 8

Percentual de Indivíduos que Recebem o Salário Mínimo

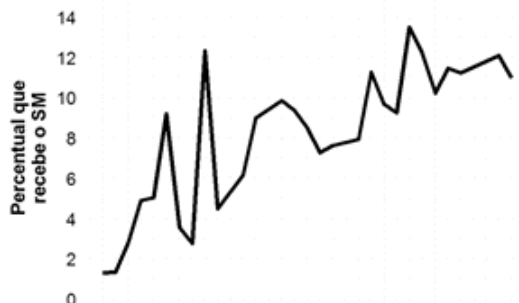

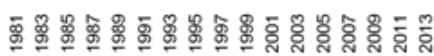

Fonte: IpeaData.

DADOS - Revista de Ciências Sociais, Rio de Janeiro, vol. 59, n² 2, 2016 
Gráfico 9

Média dos Anos de Estudo, Coortes

Nascidas entre 1916 e 1988

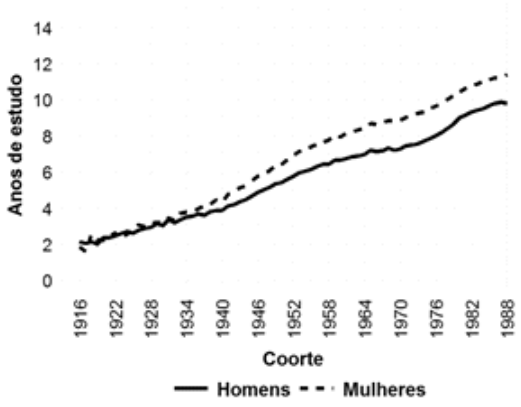

Gráfico 10

Coeficiente de Variação dos Anos de Estudo, Coortes Nascidas entre

1916 e 1988

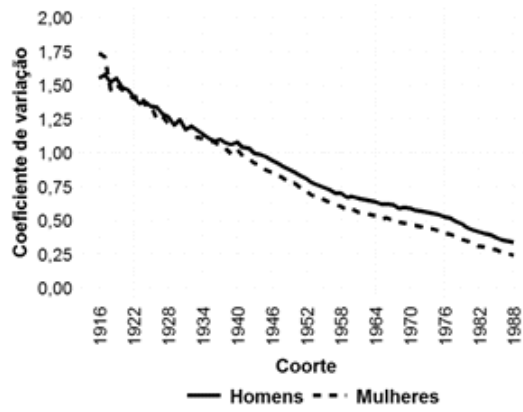

Fonte: PNADs 1981-2013; elaboração própria.

Ramos e Reis, 1995; Ulyssea e Foguel, 2006; Soares, 2002; Firpo e Reis, 2007), e indiretamente, indexando aposentadorias, pensões e transferências (Saboia, 2007). Até os anos 1990, seu valor servia de referência para diversas faixas salariais (Neri, 1997). Por isso, alguns estudos consideram como beneficiários também os que recebem múltiplos do SM (Neri, 1997; Firpo e Reis, 2007; Neri, Gonzaga e Camargo, 2010). Outros restringem os beneficiários àqueles que recebem rendimentos exatamente iguais ou próximos ao seu valor (Ramos e Reis, 1995). Utilizarei os valores do SM vigentes no período de aplicação das PNADs e o percentual de indivíduos beneficiados diretamente (ver seção seguinte).

Encontrar características de coorte é tarefa mais difícil - devem ser aspectos não ligados meramente a conjunturas e ao ciclo de vida e constantes dentro de cada coorte. A estrutura ocupacional e o pertencimento a classes sociais, por exemplo, não poderiam ser considerados: a distribuição dos indivíduos entre ocupações é uma fotografia instantânea de um processo dinâmico.

As características educacionais podem cumprir bem esse papel. Em boa medida, os indivíduos interrompem seu ciclo de escolarização quando atingem a fase adulta; assim, o nível de educação após os 25 anos de idade é razoavelmente constante. É verdade que alguns indivíduos de coortes mais recentes continuam seus estudos até um pouco mais, mas isso não interfere no padrão predominante. A distribuição 
da educação passa a ser marca geracional. Ao longo das coortes, não apenas a média de anos de estudos se elevou, como também houve homogeneização educacional. A decisão por utilizar apenas educação como medida direta se baseia em outros estudos (cf. Oliveira e RiosNeto, 2004) e também porque essa variável é capaz de captar quase toda a variação associada às coortes.

\section{METODOLOGIA}

\section{Modelos}

Como mencionado, dos seis modelos utilizados, quatro aplicam restrição da forma funcional e dois medidas diretas. Todos os resultados serão apresentados graficamente como valores preditos (devido à imensa quantidade de coeficientes, é improdutivo apresentar tabelas de regressão), em figuras que se assemelharão visualmente aos Gráficos 1, 2A e 2B. Os detalhes técnicos estão no Apêndice.

Modelos restritos tradicionais. O Modelo 1 é uma aplicação da proposta de Mason et al. (1973). Trata-se de uma regressão em que cada idade, período e coorte é uma variável dummy. A restrição é assumir que os efeitos de 2012 são iguais aos de 2013 (com base nos dados descritivos). O Modelo 2 é uma replicação parcial de Firpo, Gonzaga e Narita (2003). Assume-se que os efeitos de período são choques conjunturais com média zero.

Modelos com medidas diretas. O Modelo 3 substitui as variáveis de período pelos indicadores de inflação, crescimento econômico, valor e abrangência do salário mínimo. O Modelo 4 traz medidas diretas para coorte.

Modelos restritos da literatura recente. O Modelo 5 é o Estimador Intrínseco proposto por Yang, Fu e Land (2004). O Modelo 6 é baseado no HAPC, de Yang e Land (2006). Mas não se trata de um modelo hierárquico. Idades são tratadas como efeitos fixos; período e coorte como efeitos aleatórios.

Todos os modelos são estimados a partir de dados agregados por idade e período (dados semelhantes ao Quadro 1A).

\section{Dados}

Utilizo os dados das PNADs de 1981 a 2013, selecionando homens e mulheres que têm rendimentos mensais do trabalho principal da se- 
mana de referência diferentes de zero e possuem idades entre 25 e 65 anos. Para a escolaridade na década de 1980, apliquei a correção proposta por Soares e Lima (2002). As análises foram realizadas utilizando pesos analíticos (sem expansão). Foram excluídos casos das zonas rurais da região Norte nas PNADs posteriores a 2004, de modo a tornar a cobertura idêntica ao desenho de 1981-2003. As variáveis de rendimento foram deflacionadas segundo os deflatores de Corseuil e Foguel (2002).

Dados sobre inflação foram coletados no IpeaData. Dados sobre o PIB per capita foram obtidos no site do Banco Central. Para identificar os beneficiários do SM, tomo seus valores nominais vigentes no período de aplicação das PNADs e os arredondo para as dezenas superiores e inferiores mais próximas para levar em conta as preferências digitais e arredondamentos feitos pelos entrevistados. Assumo que são beneficiários aqueles compreendidos nesse intervalo. Devido à alta inflação entre 1987 e 1993, houve reajustes mensais em vários momentos. Deste modo, quando a PNAD ocorre pouco depois de um reajuste, considero também os valores nominais do mês anterior. A PNAD de 1982 tem como período de referência um lapso de quase três meses, dentro do qual houve reajuste. Para esse ano específico, os dois valores são indicativos de recebimento do salário mínimo.

Os códigos em $\mathrm{R}$ para a replicação completa podem ser requisitados ao autor.

\section{RESULTADOS}

É necessário proceder testes para avaliar se todas as dimensões IPC são empiricamente distinguíveis (Reither et al., 2015a e 2015b; Bell e Jones, 2015). Primeiramente, analisa-se os gráficos univariados (Gráficos 1 , 2A e 2B). É desejável que os formatos sejam diferentes - o que sugere, prima face, que idade, período e coorte operam de modo relativamente independente. Também é recomendado estimar modelos com todas as combinações de uma e duas variáveis IPC (ou seja, I, P, C, IP, IC e PC). Medidas de ajuste auxiliam na identificação da dimensionalidade. Os testes realizados apontam que, neste caso, as três dimensões importam (ver Apêndice).

Os gráficos de idade informam o valor do Theil-L, quando período e coorte são mantidos constantes em seus valores médios. Ao redor das linhas de tendência, uma área em cinza traz os intervalos de $99 \%$ de confiança ${ }^{5}$. 
Desigualdade de Rendimentos do Trabalho no Curto e no Longo Prazo...

\section{Gráfico 11}

Efeitos de Idade

Gráfico 11A - Modelo 1

(Mason et al., 1973) 2012=2013

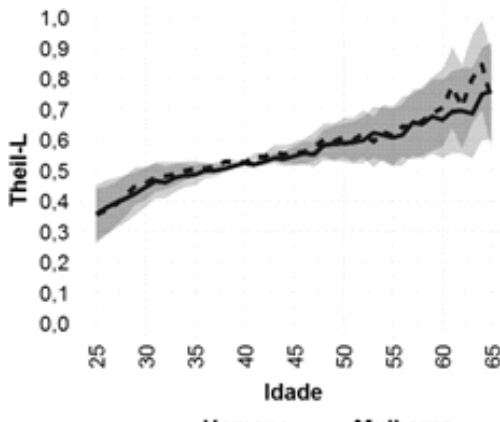

Gráfico 11C - Modelo 3

(Medidas Diretas de Período)

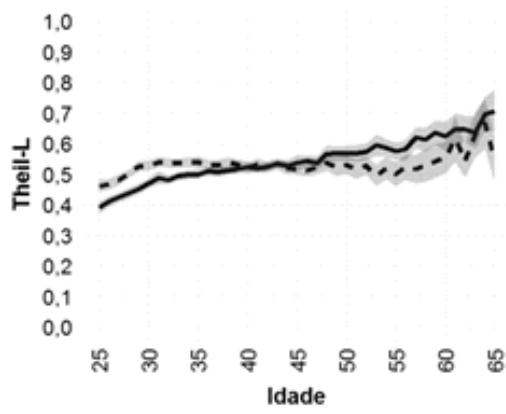

— Homens - - Mulheres

Gráfico 11E - Modelo 5

(Estimador Intrínseco)

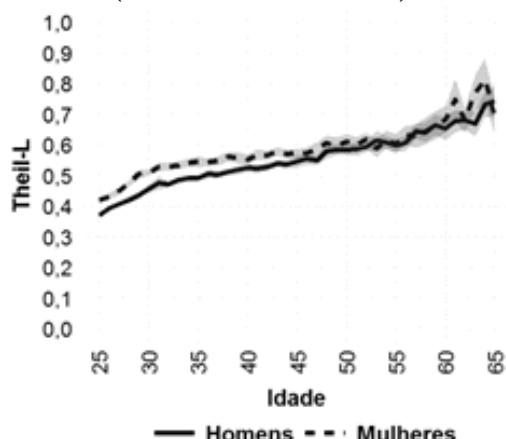

Gráfico 11B - Modelo 2

(Deaton e Paxson, 1993)

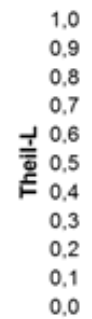

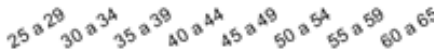
Idade

— Homens - - Mulheres

Gráfico 11D - Modelo 4

(Medidas Diretas de Coorte)

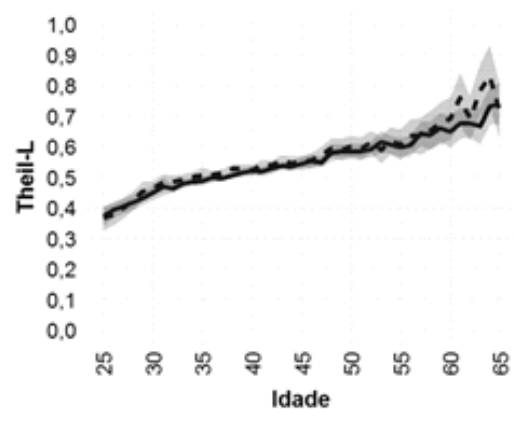

— Homens - - Mulheres

Gráfico 11F - Modelo 6

(Efeitos Mistos)

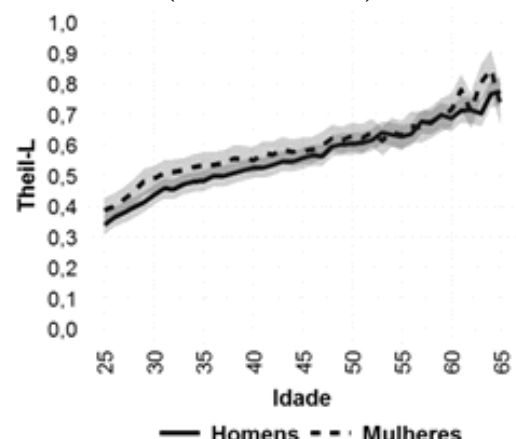

Fonte: PNADs 1981-2013; elaboração própria. 
Destaca-se a convergência entre os Modelos 1, 4, 5 e 6: eles sugerem que o ciclo de vida eleva a desigualdade em todas as coortes e períodos, e que isso é semelhante para homens e mulheres. Ela cresce acentuadamente dos 25 aos 30 anos de idade - possivelmente, em decorrência do fim da escolarização e ganho inicial de experiência. A teoria do capital humano argumenta que é justamente nessa fase que os retornos pelo on-the-job training crescem rápido, abrindo um gap entre mais e menos qualificados. Há nova aceleração depois dos 55 anos, que mantém correlação com o ciclo decrescente dos rendimentos e com a saída do mercado de trabalho por aposentadorias. Ao final do percurso, o Theil-L é duas vezes maior do que era aos 25 anos.

Vale notar que, para as mulheres, os Modelos 2 e 3 (Gráficos 11B e 11C) apresentam efeitos quase nulos (a linha horizontal sugere que nada se altera com a idade) - algo implausível tanto do ponto das teorias sociológicas sobre vantagens cumulativas (DiPrete e Eirich, 2006), quanto econômicas (Mincer, 1974). Esses dois modelos apresentarão outras anomalias, indicando que são impróprios para descrever o grupo feminino.

\section{Gráfico 12}

Efeitos de Período
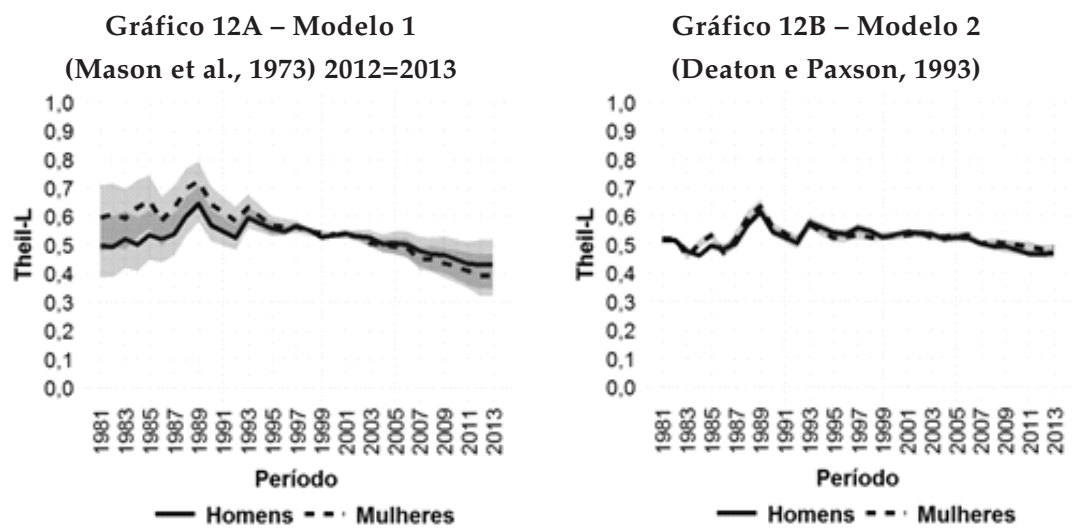

Todos os gráficos de período trazem o levante do Theil-L na década de 1980, menos volatilidade a partir de 1989 e algum declínio de 1999 em diante, conforme também verificado nas análises descritivas. Para os homens, a diferença fundamental entre esses resultados e o Gráfico 1 é a ausência de uma tendência clara. Todos os modelos mostram que os efeitos de período flutuam sobre um mesmo patamar. O crescimento e 
Gráfico 12C - Modelo 3

(Medidas Diretas de Período)

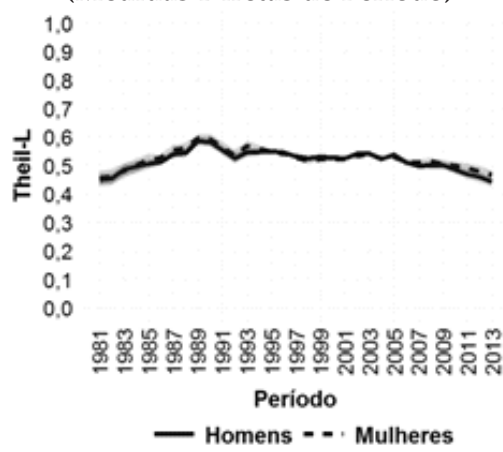

Gráfico 12E - Modelo 5

(Estimador Intrínseco)

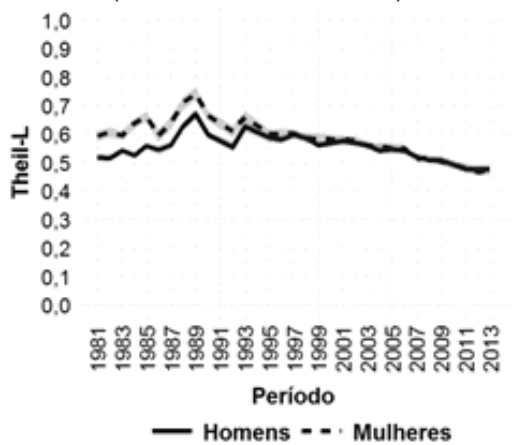

Gráfico 12D - Modelo 4

(Medidas Diretas de Coorte)

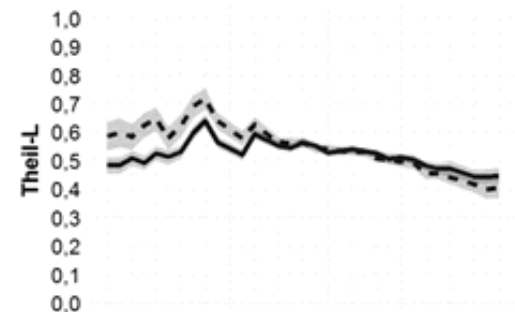

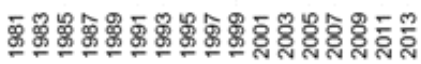

Periodo

— Homens - - Mulheres

Gráfico 12F - Modelo 6

(Efeitos Mistos)

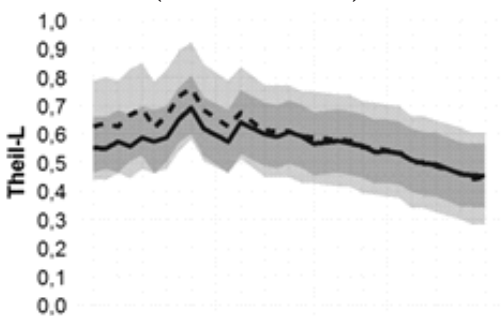

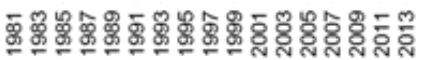

Periodo

— Homens - - Mulheres

Fonte: PNADs 1981-2013; elaboração própria.

a queda das desigualdades parecem ter feito com que 2013 fosse muito semelhante a 1981. Entre as mulheres, por sua vez, detectamos um decréscimo geral do Theil-L-indicado pelos modelos 1, 4, 5 e 6 . A presença de tendências de período é uma grave violação dos pressupostos do Modelo 2, de que toda mudança ocorreria apenas através das coortes. Isso mina sua validade para as mulheres; mas não para os homens.

Contrastando com os demais, o Modelo 3 (Medidas de Período) tem comportamento quase idêntico para os dois grupos de sexo, o que sugere um ajuste estatístico inadequado. Possivelmente, os eventos que afetam homens e mulheres não são os mesmos (o que mereceria uma investigação mais detida no futuro). Além disso, seus resultados não reproduzem as volatilidades esperadas, sugerindo que as medidas selecionadas não contemplam todos os fatores de período. 
Gráfico 13

Efeitos de Coorte

Gráfico 13A - Modelo 1

(Mason et al., 1973) 2012=2013

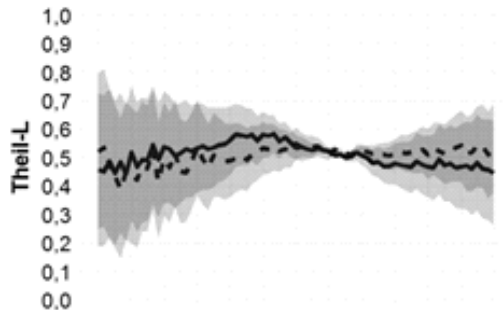

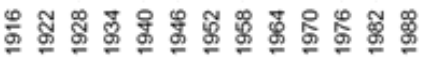
Coorte

- Homens - - Mulheres

Gráfico 13C - Modelo 3

(Medidas Diretas de Período)

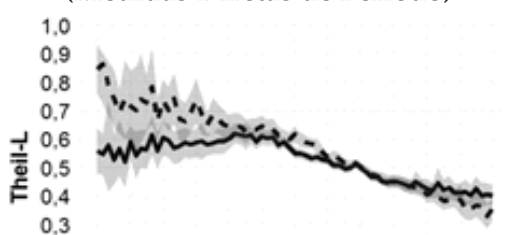

0,2

0.1

0.0

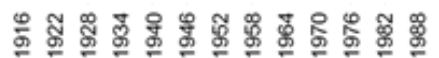
Coorte

— Homens - - Mulheres

Gráfico 13E - Modelo 5

(Estimador Intrínseco)

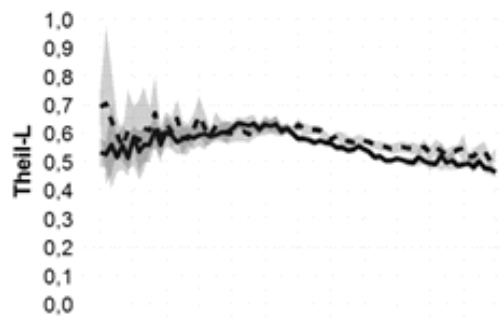

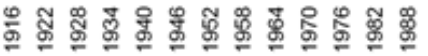
Coorte

- Homens - - Mulheres
Gráfico 13B - Modelo 2

(Deaton e Paxson, 1993)

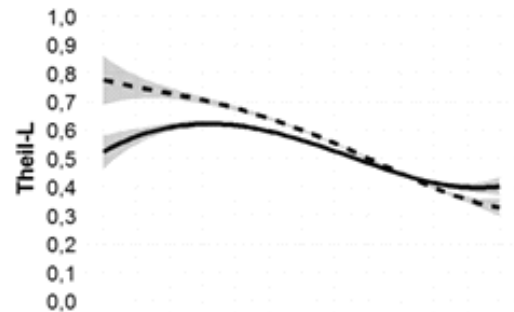

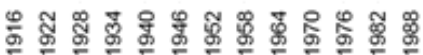
Coorte

— Homens - - Mulheres

Gráfico 13D - Modelo 4

(Medidas Diretas de Coorte)

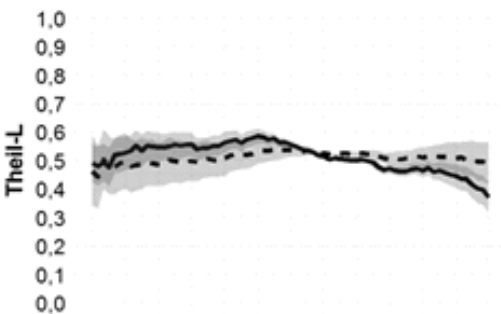

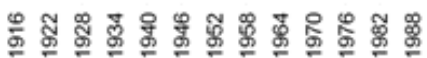
Coorte

- Homens - - Mulheres

\section{Gráfico 13F - Modelo 6 \\ (Efeitos Mistos)}

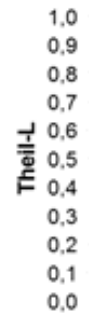

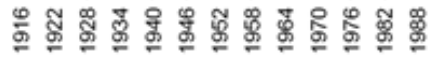
Coorte

- Homens - - ' Mulheres

Fonte: PNADs 1981-2013; elaboração própria. 
Passo aos resultados sobre coortes. Entre os homens, observa-se que, de 1916 a 1950, as gerações se tornaram cada vez mais desiguais. Há correlação entre esse levante e os processos de urbanização e industrialização (Comin, 2015). Nascidos em 1916 entram no mercado aproximadamente no início dos anos 1930, quando se aceleram as transformações na estrutura produtiva. As coortes de 1945 a 1950 são justamente aquelas que eram jovens durante o período do "Milagre Econômico" (1968-1973) - o que sugere que tinham mais condições de obter qualificação e se situavam numa etapa da vida com maior liberdade para decidir sobre carreira, migração, matrimônio e reprodução. Nessas quatro décadas de intensas transformações (1930 a 1970), os indivíduos dessas coortes adentraram o mercado de trabalho tornando-se crescentemente heterogêneos.

É verdade que a qualificação da mão de obra é critério central do recrutamento para os setores secundário e terciário. Assim, faz sentido pensar que a característica fundamental das coortes a guiar esse processo seja o seu estoque de capital humano. De fato, o Modelo 4 acompanha os demais, mostrando que as informações educacionais são boas medidas diretas das coortes. Por esta razão, faz sentido pensar que o movimento de crescimento da desigualdade durante o Milagre Econômico tenha relação com um desequilíbrio entre oferta e demanda educacional, como sugeriu Langoni (1973). Como a escolarização se interrompe, em geral, após os 25 anos de idade; apenas no longo prazo, com a substituição de coortes, a escassez de qualificação se resolveria e veríamos os retornos desproporcionais desaparecerem. Contudo, ainda que o Milagre possa ter representado um choque conjuntural (logo, um efeito de período) sobre a demanda por educação, as desigualdades intrageracionais de rendimentos do trabalho já vinham crescendo silenciosamente. Apesar de não termos dados especificamente para aqueles anos, observamos gerações crescentemente díspares, o que é sintoma de transformações sociais mais amplas. Se de fato houve uma skill-biased technological change, ela se arrastou por 40 anos ou mais, e não apenas cinco.

Segundo a lógica aqui exposta, faz pouco sentido que os efeitos da educação se manifestem no curto prazo - algo que coloca parcialmente em xeque a interpretação corrente sobre a queda da desigualdade na década de 2000 (por exemplo, Ferreira et al., 2006), segundo a qual a escolarização teria tido papel preponderante sobre os movimentos de curto prazo dos indicadores. No mínimo, aquelas estimativas superestimam 
o papel da educação, deixando de distinguir entre oferta e demanda no mercado de trabalho.

Ademais, não podemos assumir que a educação seja o único componente associado às coortes. Como discutido anteriormente, encontrar essas características nem sempre é simples: deve ser um traço que permanece constante dentro de cada coorte, a despeito do envelhecimento e dos períodos - variando apenas entre coortes. Sem mais covariáveis e medidas diretas, a educação acaba por subsumir outros efeitos.

Para as mulheres, os modelos apontam grande estabilidade das desigualdades internas às coortes, um resultado que julgo contraintuitivo. Eu esperaria que, com o crescimento da participação feminina, cada nova geração de mulheres encontrasse no mercado de trabalho vias pavimentadas pelas gerações precedentes - deste modo, com maiores possibilidades de inserção ocupacional e desenvolvimento de carreiras, a desigualdade aumentaria ao longo das coortes. No entanto, isso não ocorre. Em praticamente todos os gráficos, a linha tracejada é horizontal, mostrando que houve pouca variação. Ao final, a observada queda das desigualdades entre as mulheres (Gráfico 1) é fundamentalmente um fenômeno de período. Esse ponto merece mais investigações.

Podemos agora usar os efeitos IPC separados para propor uma decomposição do movimento observado do Theil-L. Essa decomposição é resposta para três questões contrafactuais simples:

1) Como seria o movimento das desigualdades entre 1981 e 2013 se as características de período e coorte tivessem se mantido tais como eram em 1981, deixando apenas os efeitos de idade variarem?

2) E se apenas as características de período tivessem variado?

3) E se apenas as características de coorte tivessem variado?

A resposta à primeira questão informará sobre a contribuição específica dos efeitos de idade (isto é, da evolução da estrutura etária); a segunda resposta, sobre a contribuição dos efeitos de período; e, por fim, a terceira, dos efeitos de coorte (da substituição de gerações). Para isso, produzimos valores preditos para três diferentes perfis: o primeiro faz variar apenas a idade, mantendo período e coorte constantes nos valores de 1981 - e assim por diante. As estimações serão feitas a partir dos Modelos 4, 5 e 6 (o Modelo 1 traz erros-padrão muito elevados e os Modelos 2 e 3 não são aplicáveis às mulheres). 
Desigualdade de Rendimentos do Trabalho no Curto e no Longo Prazo...

\section{Gráfico 14}

Valores Contrafactuais
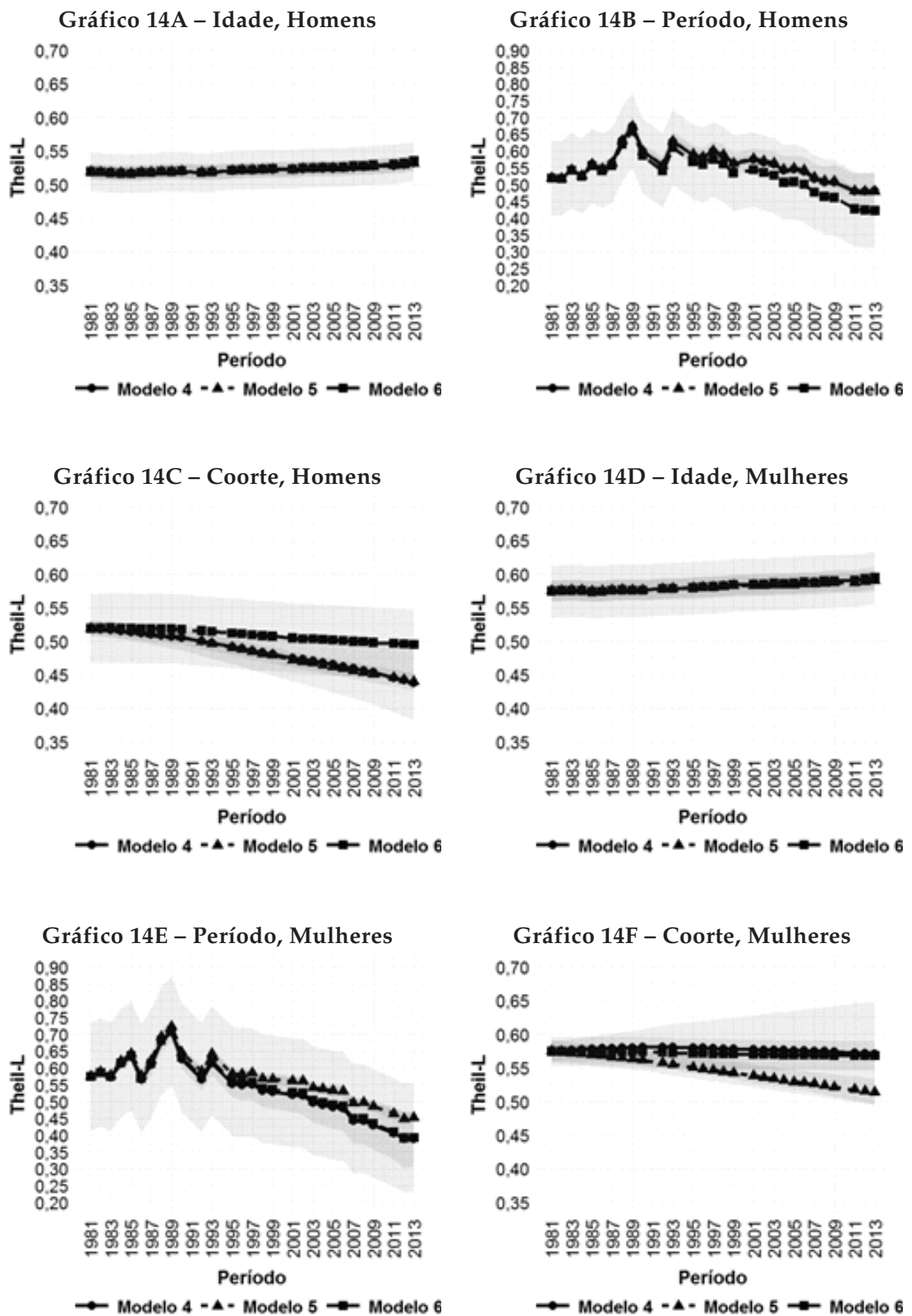

Fonte: PNADs 1981-2013; elaboração própria. 
Em todos os modelos, os efeitos de idade contribuíram pouco para as tendências entre 1981 e 2013. Sabemos, pelo Gráfico 11, que o curso de vida aponta para mais desigualdades. Era de se esperar que o envelhecimento populacional elevasse os indicadores. Além disso, algum efeito seria esperado particularmente para as mulheres, que alteram radicalmente a inserção econômica por idade (Guimarães, Barone e Brito, 2015; Hoffman e Leone, 2004). Podemos pensar que o envelhecimento e a equalização etária da força de trabalho reduziram os retornos pela experiência, trazendo igualdade. Uma aposta possível é a de que esses dois efeitos (ciclo de vida e equalização) tenham se anulado.

Os Gráficos 14B e 14E trazem cenários contrafactuais nos quais apenas atuam os efeitos de período. As linhas delineiam um movimento muito semelhante àquele do Gráfico 1 e da série do Gráfico 12. Os Modelos 4 (Medidas de Coorte) e 5 (Estimador Intrínseco) mostram que, entre os homens, o saldo dos efeitos é diminuto: em 2013, o Theil-L fica apenas um pouco abaixo (0,04 ponto) do nível de 1981. Considerando a imprecisão, nem mesmo é possível afirmar que seja diferente de zero. Mas isso não pode ocultar o fato de que os efeitos de período cumpriram um papel central: produziram e desfizeram a concentração de renda, evidenciando um aspecto volátil do mercado de trabalho. Se nos detemos apenas de 1989 em diante, os efeitos de período foram responsáveis pela queda de aproximadamente 0,19 ponto no Theil-L-algo expressivo. Consequentemente, a substituição de coortes é o que teve maior peso no grupo masculino, ao longo dos anos analisados. Segundo os Modelos 4 e 5, quase a totalidade da queda observada desde 1981 (e metade da observada de 1989 em diante) deve-se justamente aos efeitos de coorte.

Para as mulheres, os Modelos 4 e 6 indicam aquilo que já havia sido antevisto: a queda das desigualdades teria se dado principalmente como efeito de período, ou seja, uma equalização dos rendimentos independentemente do grupo etário e coortes. O Gráfico 14E mostra que esses efeitos de período atuaram, de forma contínua, ao menos desde 1993.

\section{DISCUSSÕES E CONSIDERAÇÕES FINAIS}

Neste artigo, investiguei a contribuição de efeitos de longo e curto prazo sobre as tendências de desigualdade da renda do trabalho. Os resultados produzidos foram robustos e sobreviveram a diferentes especifi- 
cações de modelos. Essa convergência traz segurança quanto às interpretações e reforçam a relevância do longo prazo.

Entre os homens, a queda observada das desigualdades ao longo dos últimos 35 anos foi sobretudo um processo de longo prazo, que se fez sentir lentamente, conforme gerações se substituíram no mercado de trabalho. As coortes, de 1916 a 1950, foram crescentemente mais desiguais - seguindo a história da industrialização e urbanização no Brasil. As coortes nascidas depois de 1955, por seu turno, tornaram-se mais homogêneas. Esses efeitos, no entanto, são agregados de diversos processos (indistinguíveis empiricamente, por razões metodológicas e limites dos dados). Entretanto, é certo que o avanço e a equalização educacional cumpriram papéis importantíssimos. Os efeitos conjunturais e políticos de período tiveram soma zero. Foram muito intensos, elevando as desigualdades na década de 1980 e, nos anos 2000, mitigaram as consequências das crises e instabilidades.

O quadro é bastante distinto para as mulheres. A concentração de renda entre coortes permaneceu razoavelmente constante. A mudança nos padrões de distribuição de rendimentos entre as mulheres não esteve apenas associada ao avanço das oportunidades educacionais. Isso coloca um desafio à noção de "corrida" entre qualificação e tecnologia. A desigualdade de rendimentos do trabalho efetivamente caiu entre as mulheres como fruto de efeitos de período. Ou seja, entre 1981 e 2013, houve um processo equalizador atuando sobre todo o grupo feminino, independentemente da idade ou geração. Os fatores por trás desses efeitos devem ser investigados. Por certo, as medidas diretas que elenquei tiveram algum papel; mas se mostraram insuficientes e não captaram as tendências diferenciais por gênero.

Importante pontuar que estudos recentes colocaram em xeque conclusões anteriormente vigentes sobre as desigualdades de renda no Brasil e também as fontes de dados comumente utilizadas. Medeiros, Souza e Castro (2014 e 2015) e Souza (2014), utilizando dados do Imposto de Renda (IR), mostraram que as pesquisas por survey subestimam fortemente as rendas mais elevadas. Medeiros e Souza (2014), agregando dados do Censo 2010 e do IR, mostram que o cenário nos anos 2000 é, no mínimo, de estagnação - e não de queda.

É importante argumentar acerca da diferença entre as noções de redistribuição, por um lado, e redução das desigualdades, de outro. "Redistribuição" ou "transferência" é qualquer alteração na apropriação das 
frações de renda entre grupos. Se uma parte da renda apropriada pelos estratos médios é realocada para os mais pobres e outras parte para os mais ricos, houve redistribuição. Isso muda qualitativamente o quadro da desigualdade, mas nem todos os indicadores acusarão uma mudança quantitativa. Um índice escalar de desigualdade faz referência ao quadro global. A "estabilidade da desigualdade" é resultado justamente de um quadro como aquele: redistribuição da classe média para os mais pobres simultânea a processos de concentração no topo (cf. Souza e Medeiros, 2015).

No topo e na base, não estamos falando das mesmas formas de procura de emprego, dos mesmos tipos de vínculo, dos mesmos modos de competição, nem das mesmas instituições e modos de regulação. O ponto de corte em que surveys deixam de captar adequadamente o rendimento dos quantis superiores é possivelmente também um ponto em que começam a prevalecer causas e consequências qualitativamente distintas das desigualdades de rendimentos. Analisar a "base" da distribuição permanece relevante, porém não nos mesmos termos que antes. Torna-se imperiosa a necessidade de qualificar os diagnósticos e circunscrevê-los.

(Recebido para publicação em maio de 2015)

(Reapresentado em novembro de 2015)

(Aprovado para publicação em março de 2016) 


\section{NOTAS}

1. No Brasil, a maior parte dos estudos utilizando métodos IPC se dedicou a outros temas: educação (Collares, 2010; Guimarães e Rios-Neto, 2011), status ocupacional (Ribeiro, 2010), religião (Almeida e Barbosa, 2013; Coutinho e Golgher, 2014), atividade econômica (Leme e Wajnman, 1999; Rios-Neto e Oliveira, 1999; Oliveira e Rios-Neto, 2004), desemprego (Reis e Gonzaga, 2006), jornada de trabalho (Gonzaga, Machado e Machado, 2003) e pobreza (Ribas, 2007).

2. Outros recortes seriam possíveis, mas nem sempre adequados. Uma análise por regiões, por exemplo, implicaria a suposição de que as populações regionais são estáveis, alterando-se apenas em função do crescimento vegetativo. Contudo, o intenso fluxo migratório (Cunha, 2015) viola esse suposto.

3. Ver discussão sobre os dados utilizados na seção sobre metodologia.

4. No caso de uma estimação por OLS, a matriz $X^{\prime} X$ não terá posto completo, fazendo com que a inversa $\left(X^{\prime} X\right)^{-1}$ não exista. O problema persiste mesmo em modelos com termos interativos ou não lineares.

5. No Modelo 1 há intensa perda de graus de liberdade. Por isso, os intervalos de confiança são muito maiores. Para ele, os ICs são de $80 \%$. 


\section{REFERÊNCIAS BIBLIOGRÁFICAS}

ALMEIDA, Ronaldo; BARBOSA, Rogério. (2013), “Transmissão Religiosa nos Domicílios Brasileiros", in F. Teixeira; R. Menezes (orgs.), Religiões em Movimento: O Censo de 2010. Petrópolis, Vozes.

BACHA, Edmar. (1978a), "Além da Curva de Kuznets: Crescimento e Desigualdade". Economia, vol. 2, no 2, pp. 173-200.

. (1978b), "Hierarquia e Remuneração Gerencial”, in R. Tolipan; A. Tinelli (orgs.), A Controvérsia sobre a Distribuição de Renda e Desenvolvimento. Rio de Janeiro, Zahar.

BACHA, Edmar; TAYLOR, Lance. (1980), “Brazilian Income Distribution in the 1960s: Acts, Model Results, and the Controversy", in L. Taylor et al. (orgs.), Models of Growth and Distribution for Brazil. Oxford, Oxford University Press.

BARBOSA, Rogério J.; PRATES, Ian. (2015), “Mercado de Trabalho e Estrutura das Desigualdades na Região Metropolitana de São Paulo: 1981-2011”, in E. Marques (org.), A Metrópole de São Paulo no Século XXI: Espaços, Heterogeneidades e Desigualdades. São Paulo, Ed. Unesp.

BARBOZA, André. (2008), A Relação entre Inflação e Distribuição de Renda. Dissertação (Mestrado em Economia), Universidade de São Paulo, São Paulo.

BARROS, Ricardo et al. (2006), "A Queda Recente da Desigualdade de Renda no Brasil”, in R. P. de Barros et al. (orgs.), Desigualdade de Renda no Brasil: Uma Análise da Queda Recente. Brasília, Ipea.

BARROS, Ricardo; FOGUEL, Miguel; ULYSSEA, Gabriel (orgs.). (2006), Desigualdade de Renda no Brasil: Uma Análise da Queda Recente. Brasília, Ipea. vol. 1.

BELL, Andrew; JONES, Kelvyn. (2013a), “The Impossibility of Separating Age, Period and Cohort Effects". Social Science \& Medicine, vol. 93, pp. 163-165.

. (2013b), “Another 'Futile Quest'? A Simulation Study of Yang and Land's Hierarchical Age-Period-Cohort Model". Demographic Research, vol. 30, pp. 333-360.

. (2014), “Don't Birth Cohorts Matter? A Commentary and Simulation Exercise on Reither, Hauser, and Yang's (2009) Age-Period-Cohort Study of Obesity". Social Science \& Medicine, vol. 101, pp. 176-180.

. (2015), "Should Age-Period-Cohort Analysts Accept Innovation without Scrutiny? A Response to Reither, Masters, Yang, Powers, Zheng and Land". Social Science E Medicine, vol. 128, pp. 331-333.

BLAU, Peter; DUNCAN, Otis. (1967), The American Occupational Structure. New York, John Wiley \& Sons.

CARDOSO, Eliana. (1993), “Cyclical Variations of Earnings Inequality in Brazil”. Revista de Economia Política, vol. 13, no 4, pp. 112-124.

; BARROS, Ricardo; URANI, André. (1993), “Inflation and Unemployment as Determinants of Inequality in Brazil: The 1980". Texto para Discussão, no 298, Rio de Janeiro, Ipea. 
CARVALHAES, Flavio et al. (2014), “Os Impactos da Geração de Empregos sobre as Desigualdades de Renda: Uma Análise da Década de 2000". Revista Brasileira de Ciências Sociais, vol. 29, no 85, pp. 79-221.

CARVALHAES, Flavio; SOUZA, Pedro. (2014), "Análise de Classe e a Queda da Desigualdade de Renda do Trabalho no Brasil”. Plural, vol. 21, no 2, pp. 77-107.

CHAUVEL, Louis; SCHRÖDER, Martin. (2014), "Generational Inequalities and Welfare Regimes". Social Forces, vol. 92, no 4, pp. 1259-1283.

COLLARES, Ana. (2010), Educational Inequalities and the Expansion of Postsecondary Education in Brazil, from 1982 to 2006. Tese (Doutorado em Sociologia), Universidade de Wisconsin, Madison.

COMIN, Alvaro. (2015), “Desenvolvimento Econômico e Desigualdades no Brasil:1960-2010", in M. Arretche (org.), Trajetórias das Desigualdades. Como o Brasil Mudou nos Últimos Cinquenta Anos. São Paulo, Editora da Unesp, pp. 367-394.

CORSEUIL, Carlos; FOGUEL, Miguel. (2002), “Uma Sugestão de Deflatores para Rendas Obtidas a partir de Algumas Pesquisas Domiciliares do IBGE". Texto para Discussão, no 897, Rio de Janeiro, Ipea.

COUTINHO, Raquel; GOLGHER, André. (2014), “The Changing Landscape of Religious Affiliation in Brazil between 1980 and 2010: Age, Period, and Cohort Perspectives". Revista Brasileira de Estudos da População, vol. 31, no 1, pp. 73-98.

CUNHA, José. (2015), “A Migração Interna no Brasil nos Últimos Cinquenta Anos: (Des)continuidades e Rupturas", in M. Arretche (org.), Trajetórias das Desigualdades. Como o Brasil Mudou nos Últimos Cinquenta Anos. São Paulo, Editora da Unesp, pp. 279-307.

DEATON, Angus; PAXSON, Christina. (1993), "Saving, Growth and Aging in Taiwan". NBER Working Paper no 4330.

DiPRETE, Thomas. (2007), "What Has Sociology to Contribute to the Study of Inequality Trends? A Historical and Comparative Perspective". American Behavioral Scientist, vol. 50, no 5, pp. 603-618.

; EIRICH, Gregory. (2006), “Cumulative Advantage as a Mechanism for Inequality: A Review of Theoretical and Empirical Developments". Annual Review of Sociology, vol. 32, pp. 271-297.

FERREIRA, Francisco et al. (2006), "A Ascensão e Queda da Desigualdade de Renda no Brasil". Econômica, vol. 8, no 1, pp. 147-169.

FIENBERG, Stephen. (2013), "Cohort Analysis' Unholy Quest: A Discussion”. Demography, vol. 50, no 6, pp. 1981-1984.

FIRPO, Sergio; GONZAGA, Gustavo; NARITA, Renata. (2003), “Decomposição da Evolução da Desigualdade de Renda no Brasil em Efeitos de Idade, Período e Coorte". Pesquisa e Planejamento Econômico, vol. 33, no 2, pp. 211-252.

FIRPO, Sergio; REIS, Maurício. (2007), “O Salário Mínimo e a Queda Recente da Desigualdade no Brasil", in R. P. de Barros; M. Foguel; G. Ulyssea (orgs.), Desigualdade de Renda no Brasil: Uma Análise da Queda Recente. Brasília, Ipea, pp. 409-506. 
FISHLOW, Albert. (1972), "Brazilian Size Distribution of Income”. The American Economic Review, vol. 62, nos 1/2, pp. 391-402.

FU, Wenjiang. (2000), "Ridge Estimator in Singular Design with Application to AgePeriod-Cohort Analysis of Disease Rates". Communications in Statistics-Theory and Methods, vol. 29, no 2, pp. 263-278.

GANDRA, Rodrigo. (2005), “O Debate sobre a Desigualdade de Renda no Brasil: Da Controvérsia dos Anos 1970 ao Pensamento Hegemônico nos Anos 1990". História Econômica e História de Empresas, vol. 8, no 1, pp. 139-162.

GLENN, Norval. (1976), “Cohort Analysts' Futile Quest: Statistical Attempts to Separate Age, Period and Cohort Effects". American Sociological Review, vol. 41, no 5, pp. 900-904.

. (1989a), “A Caution about Mechanical Solution to the Identification Problem in Cohort Analysis: Comment on Sasaki and Suzuki". American Journal of Sociology, vol. 95, no 3, pp. 754-761.

. (1989b), "A Flawed Approach to Solving the Identification Problem in the Estimation of Mobility Effect Models: A Comment on Brody and McRae". Social Forces, vol. 67, no 3, pp. 789-795.

GOLDIN, Claudia; KATZ, Lawrence. (2009), The Race between Education and Technology. Boston, MA, Harvard University Press.

GONZAGA, Gustavo; MACHADO, Ana; MACHADO, Danielle. (2003), “Horas de Trabalho: Efeitos Idade, Período e Coorte". Texto para Discussão № 473, Departamento de Economia, PUC-Rio.

GUIMARÃES, Nadya; BARBOSA, Rogério; CARVALHAES, Flavio. (2012), Efeitos das Desigualdades de Origem sobre a Procura de Emprego. Trabalho apresentado no 36응 Encontro Anual da Anpocs, Águas de Lindóia, 21-25 de outubro.

GUIMARÃES, Nadya; BARONE, Leonardo; BRITO, Murillo. (2015), “Mercado e Mercantilização do Trabalho no Brasil (1960-2010)", in M. Arretche (org.), Trajetórias das Desigualdades. Como o Brasil Mudou nos Últimos Cinquenta Anos. São Paulo, Editora da Unesp, pp. 279-307.

GUIMARÃES, Raquel; RIOS-NETO, Eduardo. (2011), “Comparação entre Metodologias de Idade-Período-Coorte para o Estudo de uma Medida da Progressão Escolar no Brasil". Revista Brasileira de Estudos de População, vol. 28, no 2, pp. 349-367.

HASENBALG, Carlos; SILVA, Nelson. (2003), Origens e Destinos: Desigualdades Sociais ao longo da Vida. Rio de Janeiro, Topbooks.

HECKMAN, James; ROBB, Richard. (1985), “Using Longitudinal Data to Estimate Age, Period and Cohort Effects in Earnings Equation", in W. Mason; S. Fienberg (eds.), Cohort Analysis in Social Research. New York, Springer-Verlag, pp. 137-150.

HOFFMANN, Rodolfo. (1998), “Desigualdade e Pobreza no Brasil no Período 1979/97 e a Influência da Inflação e do Salário Mínimo". Economia e Sociedade, no11, pp. 199-221.

. (2001), "Distribuição de Renda e Crescimento Econômico". Estudos Avançados, vol. 15 , no 41, pp. 67-76. 
;DUARTE, João. (1972), “A Distribuição da Renda no Brasil”. Revista de Administração de Empresas, vol. 12, no 2, pp. 46-66.

; LEONE, Eugênia. (2004), “Participação da Mulher no Mercado de Trabalho e Desigualdade da Renda Domiciliar per capita no Brasil: 1981-2002". Nova Economia, vol.14, no 2, pp. 35-58.

KUZNETS, Simon. (1955), "Economic Growth and Income Inequality". The American Economic Review, vol. 45, no 1, pp. 1-28.

LANGONI, Carlos. (2005) [1973], Distribuição da Renda e Desenvolvimento Econômico no Brasil. 3a ed. Rio de Janeiro, FGV Editora.

LEME, Maria Carolina da S.; WAJNMAN, Simone. (1999), "Efeitos de Período, Coorte e Ciclo de Vida na Participação Feminina no Mercado de Trabalho Brasileiro", Anais do XXI Encontro Brasileiro de Econometria, Belém, vol. 2.

LUO, Liying. (2013a), "Assessing Validity and Application Scope of the Intrinsic Estimator Approach to the Age-Period-Cohort Problem". Demography, vol. 50, no 6, pp. 1943-1944.

. (2013b), Cross-classified Age-Period-Cohort Models as a Constrained Estimator. Trabalho apresentado na 141a Reunião Anual da Apha, Boston, 2-6 de novembro.

. (2013c), "Paradigm Shift in Age-Period-Cohort Analysis: A Response to Yang and Land, O'Brien, Held and Riebler, and Fienberg". Demography, vol. 50, № 6, pp. 1985-1988.

et al. (2014), "The Sensitivity of the Intrinsic Estimator to Coding Schemes: A Comment on Yang, Schulhofer-Wohl, Fu, and Land". American Journal of Sociology (forthcoming). Working paper no 2014-1.

MALAN, Pedro; WELLS, John. (1973), “Distribuição de Renda e Desenvolvimento Econômico no Brasil - Resenha Bibliográfica". Pesquisa e Planejamento Econômico, vol. 3, ำ 4 .

MANSKI, Charles. (2003), "Identification Problems in the Social Sciences and Everyday Life". Southern Economic Journal, vol. 70, no 1, pp. 11-21.

MASON, Karen et al. (1973), "Some Methodological Issues in Cohort Analysis of Archive Data". American Sociological Review, vol. 38, no 2, pp. 242-258.

MCCALL, Leslie; PERCHESKI, Christine. (2010), “Income Inequality: New Trends and Research Directions". Annual Review of Sociology, vol. 36, pp. 329-347.

MEDEIROS, Marcelo; GALVÃO, Juliana. (2014), “Educação e o Rendimento dos Ricos no Brasil". SSRN Working Paper no 2493829.

MEDEIROS, Marcelo; SOUZA, Pedro; CASTRO, Fábio. (2014), “A Estabilidade da Desigualdade de Renda no Brasil, 2006 a 2012: Estimativa com Dados do Imposto de Renda e Pesquisas Domiciliares". SSRN Working Paper no 2493877.

MEDEIROS, Marcelo; SOUZA, Pedro; CASTRO, Fábio. (2015), “O Topo da Distribuição de Renda no Brasil: Primeiras Estimativas com dados Tributários e Comparação com Pesquisas Domiciliares (2006-2012)". DADOS - Revista de Ciências Sociais, vol. 58, no 1, pp. 7-36. 
MINCER, Jacob. (1974), Schooling, Earnings and Experience. New York, Columbia University Press.

MORRIS, Martina; WESTERN, Bruce. (1999), "Inequality in Earnings at the Close of the Twentieth Century". Annual Review of Sociology, vol. 25, pp. 623-657.

MOUW, Ted; KALLEBERG, Arne. (2010), “Occupations and the Structure of Wage Inequality in the United States, 1980s to 2000s". American Sociological Review, vol. 75, no3, pp. 402-431.

NERI, Marcelo. (1995), “Sobre a Mensuração dos Salários Reais em Alta Inflação". Pesquisa e Planejamento Econômico, vol. 25, no 3, pp. 497-526.

(1997), “O Reajuste do Salário Mínimo de Maio de 1995”. Anais do XIX Encontro Brasileiro de Econometria. Rio de Janeiro, Sociedade Brasileira de Econometria.

; GONZAGA, Gustavo; CAMARGO, José. (2010), “Efeitos Informais do Salário Mínimo e Pobreza". Ensaios Econômicos, no 372, EPGE/FGV.

O'BRIEN, Robert. (2000), "Age Period Cohort Characteristic Models". Social Science Research, vol. 29, no 1, pp. 123-139.

OLIVEIRA, Ana; RIOS-NETO, Eduardo. (2004), “Modelos Idade-Período-Coorte Aplicados à Participação na Força de Trabalho: Em Busca de uma Versão Parcimoniosa". Revista Brasileira de Estudos de População, vol. 21, no 1, pp. 21-47.

PRATES, Ian; BARBOSA, Rogério. (2014), “Classes Sociais e Fechamento Social: Determinantes da Desigualdade de Renda em São Paulo". Plural, vol. 21, no2, pp. 108-138.

RAMOS, Lauro; REIS, José. (1995), “Salário Mínimo, Distribuição de Renda e Pobreza no Brasil". Pesquisa e Planejamento Econômico, vol. 25, no 1, pp. 99-114.

REIS, José. (1989), "Salário Mínimo e Distribuição de Renda no Brasil". Perspectivas da Economia Brasileira 1989. Rio de Janeiro, Ipea.

REIS, Maurício; GONZAGA, Gustavo. (2006), “Desemprego e Qualificação: Uma Análise dos Efeitos Idade, Período e Coorte". Pesquisa e Planejamento Econômico, vol. 36, no 3, pp. 367-412.

REITHER, Eric et al. (2015a), "Clarifying Hierarchical Age-Period-Cohort Models: A Rejoinder to Bell and Jones". Social Science and Medicine, vol. 145, pp. 125-128.

. (2015b), "Should Age-Period-Cohort Studies Return to the Methodologies of the 1970s?". Social Science and Medicine, vol. 128, pp. 356-365.

RIBAS, Rafael. (2007), “A Caracterização da Pobreza Urbana ao Longo do Tempo: Aplicação do Modelo Idade-Período-Coorte na Estimação das Tendências de Privações Crônica e Transitória no Brasil". Revista Brasileira de Estudos de População, vol. 24, no 1, pp. 139-161.

RIBEIRO, Carlos A. Costa. (2010), Ensino Superior e Mercado de Trabalho no Brasil: Uma Análise de Idade, Período e Coorte (IPC). Mimeo.

RIOS-NETO, Eduardo; OLIVEIRA, Ana. (1999), “Aplicação de um Modelo de Idade-Período-Coorte para a Atividade Econômica do Brasil Metropolitano". Pesquisa e Planejamento Econômico, vol. 29, no 2, pp. 243-272.

RODGERS, Willard. (1982a), "Estimable Functions of Age, Period, and Cohort Effects". American Sociological Review, vol. 47, no 6, pp. 774-787. 
. (1982b), "Reply to Comment by Smith, Mason, and Fienberg". American Sociological Review, vol. 47, no 6, pp. 793-796.

RYDER, Norman. (1965), "The Cohort as a Concept in the Study of Social Change". American Sociological Review, vol. 30, no 6, pp. 843-861.

SABOIA, João. (2007), “O Salário Mínimo e seu Potencial para a Melhoria da Distribuição de Renda no Brasil”, in R. P. de Barros; M. Foguel; G. Ulyssea (orgs.), Desigualdade de Renda no Brasil: Uma Análise da Queda Recente. Brasília, Ipea, pp. 479-497.

SILVA, Nelson do Valle. (2003), “Os Rendimentos Pessoais", in C. Hasenbalg; N. do Valle Silva (eds.), Origens e Destinos: Desigualdades Sociais ao Longo do Ciclo de Vida. Rio de Janeiro, Topbooks.

SOARES, Sergei. (2002), “O Impacto Distributivo do Salário Mínimo: A Distribuição Individual dos Rendimentos do Trabalho". Texto para Discussão no 873, Ipea.

; LIMA, Adriana. (2002), “A Mensuração da Educação nas PNADs da Década de 1990". Texto para Discussão, o 928, Ipea.

SOUZA, Pedro. (2014), “Top Incomes in Brazil, 1933-2012: A Research Note". SSRN Working Paper, no 2537026.

; MEDEIROS, Marcelo. (2015), “Top Incomes Shares and Inequality in Brazil, 1928-2012". Sociologies in Dialogue, vol. 1, no 1, pp. 119-132.

ULYSSEA, Gabriel; FOGUEL, Miguel. (2006), “Efeitos do Salário Mínimo sobre o Mercado de Trabalho Brasileiro". Texto para Discussão, no 1168, Ipea.

YANG, Yang. (2008), "Trends in U.S. Adult Chronic Disease Mortality, 1960-1999: Age, Period and Cohort Variations". Demography, vol. 45, no 2, pp. 387-416.

; FU, Wenjiang; LAND, Kenneth. (2004), “A Methodological Comparison of Age-Period-Cohort Models: The Intrinsic Estimator and Conventional Generalized Linear Models". Sociological Methodology, vol. 34, no 1, pp. 75-110.

YANG, Yang; LAND, Kenneth. (2006), “A Mixed Models Approach to the Age-PeriodCohort Analysis of Repeated Cross-section Surveys, with an Application to Data on Trends in Verbal Test Scores". Sociological Methodology, vol. 36, no 1, pp. 75-97.

. (2008), "Age-Period-Cohort Analysis of Repeated Cross-Section Surveys: Fixed or Random Effects?". Sociological Methods \& Research, vol. 36, no 3, pp. 297-326.

. (2013), Age-Period-Cohort Analysis: New Models, Methods, and Empirical Applications. New York, Chapmen \& Hall/CRC Press. 


\section{APÊNDICE}

1. Ausência de viés nos efeitos de coorte e idade quando usamos medidas diretas de período

Suponha a seguinte equação:

$$
y=\alpha+\beta_{1} P_{1}+\beta_{2} P_{2}+\gamma C+\delta A+\varepsilon
$$

$P_{1}$ e $P_{2}$ são medidas de período; $C$ representa as coortes e A as idades. $P_{2}$ é não observável. Com isso:

$$
y=\alpha+\beta_{1} P_{1}+\gamma C+\delta A+v
$$

Em que $v=\beta_{2} P_{2}+\varepsilon$. Suponha uma projeção linear de $P_{2}$ sobre as demais variáveis:

$$
P_{2}=\theta_{0}+\theta_{1} P_{1}+\theta_{2} C+\theta_{3} A+\omega
$$

Substituindo na equação anterior:

$$
\begin{gathered}
y=\left(\alpha+\beta_{2} \theta_{0}\right)+\left(\beta_{1}+\beta_{2} \theta_{1}\right) P_{1}+\left(\gamma+\beta_{2} \theta_{2}\right) C+\left(\delta+\beta_{2} \theta_{3}\right) A+\left(\varepsilon+\beta_{2} \omega\right) \\
=\tilde{\alpha}+\widetilde{\beta}_{1} P_{1}+\widetilde{\gamma} C+\delta A+\widetilde{\varepsilon}
\end{gathered}
$$

Se qualquer $\theta$ for diferente de zero, os coeficientes estimados $\left(\widetilde{\alpha}, \widetilde{\beta}_{1}, \tilde{\gamma}\right.$ e $\left.\widetilde{\delta}\right)$, serão diferentes dos "verdadeiros" $\left(\alpha, \beta_{1}, \gamma\right.$ e $\left.\delta\right)$. No entanto, se coorte $(C)$ e idade $(A)$ não forem correlacionadas com $P_{2}$ :

$$
\begin{gathered}
y=\left(\alpha+\beta_{2} \theta_{0}\right)+\left(\beta_{1}+\beta_{2}\right) P_{1}+\left(\gamma+\beta_{2} \times 0\right) C+\left(\delta+\beta_{2} \times 0\right) A+\left(\varepsilon+\beta_{2} \omega\right) \\
=\widetilde{\alpha}+\widetilde{\beta}_{1} P_{1}+\gamma C+\delta A+\widetilde{\varepsilon}
\end{gathered}
$$

Utilizando medidas de período não correlacionadas com coorte e idade, os efeitos dessas últimas variáveis não serão enviesados. Pode haver endogeneidade - no entanto, restrita às variáveis de período (por isso, não é possível analisar os efeitos de cada medida separadamente).

\section{Modelos de Regressão}

As equações são estimadas por MQO. Apenas o Modelo 6 é estimado por Máxima Verossimilhança.

\section{Modelo 1}

$$
D_{k t}=\beta_{0}+\sum_{k} \delta_{k} I_{k}+\sum_{t} \gamma_{t} P_{t_{(2012=2013)}}+\sum_{j} \varphi_{j} C_{j}+\varepsilon_{k t}
$$


No Modelo 1, os coeficientes de 2012 e 2013 são idênticos. $D_{k t}$ é o Theil-L para a idade $k$ no período $t$. $\beta_{0}$ é o intercepto, $\delta_{k}, \gamma_{t}$ e $\varphi_{j}$ são os coeficientes de idade, período e coorte. $\varepsilon_{k t}$ é o termo de erros. No Modelo 2, os períodos são tomados como choques com média zero. Essa restrição é imposta através de:

$$
P_{t}^{*}=P_{t}-\left[(t-1) P_{2}-(t-2) P_{1}\right]
$$

$P_{t}$ é a variável dummy para o período te $P_{t}^{*}$ é a dummy corrigida.

\section{Modelo 2}

(Deaton e Paxson, 1993; Firpo, Gonzaga e Narita, 2003)

$$
D_{k t}=\beta_{0}+\sum_{k} \delta_{k} I_{k_{\text {indak }}-\text { sans }}+\sum_{t} \gamma_{t} P_{t}^{*}+\varphi_{1} C_{j}+\varphi_{2} C_{j}^{2}+\varphi_{3} C_{j}^{3}+\varphi_{4} C_{j}^{4}+\varepsilon_{k t}
$$

Para aproximar do modelo de Firpo, Gonzaga e Narita (2003), a variável idade está categorizada em faixas e coorte é um polinômio de quarto grau. As coortes foram recodificadas: a mais antiga recebe o valor 0 , depois 1 etc. Os Modelos 3 e 4 trazem medidas diretas para período e coorte:

\section{Modelo 3}

$$
\begin{aligned}
D_{k t}=\beta_{0} & +\beta_{1} \log \left(\text { INPC12 }_{t}+\beta_{2} \text { PIBpercap }_{t}+\beta_{3} \text { PIBpercap }_{t}^{2}+\beta_{4} \text { CrescPIB }_{t}\right. \\
& +\beta_{5} \text { SalarioMin }_{t}+\beta_{6} \text { RecebeSM }_{+}+\sum_{k} \delta_{k} I_{k}+\sum_{j} \varphi_{j} C_{j}+\varepsilon_{k t}
\end{aligned}
$$

\section{Modelo 4}

$$
\begin{aligned}
D_{k t}= & \beta_{0}+\beta_{1} \text { MédiaEscolaridade }_{j}+\beta_{2} \text { Coef.Var.da Escolaridade }_{j} \\
& +\beta_{2} \text { Coef.Var.da Escolaridade }_{j}^{2}+\sum_{k} \delta_{k} I_{k}+\sum_{t} \gamma_{t} P_{t}+\varepsilon_{k t}
\end{aligned}
$$

O Modelo 5 é o Estimador Intrínseco (Yang et al., 2004).

\section{Modelo 5}

$$
D_{k t}=\mu+\sum_{k} \delta_{k} I_{k}+\sum_{t} \gamma_{t} P_{t}+\sum_{j} \varphi_{j} C_{j}+\varepsilon_{k t}
$$

Vale expor aqui seus procedimentos de estimação. O objetivo de uma regressão é solucionar $X^{t} X b=X^{t} y$. Como $X^{t} X$ é singular, a solução completa é.

$$
b=b_{1}+r b_{0}
$$


Em que $b_{1}$ é a solução particular, $b_{0}$ é uma base normalizada do espaço nulo $\left(\left\|b_{0}\right\|=1\right)$ e $r$ é qualquer escala Real. O Estimador Intrínseco é obtido pelo valor de $r$ que minimiza a norma de $\boldsymbol{b}$ :

$$
\begin{gathered}
r_{I E}=\underset{r}{\operatorname{argmin}}\left(b_{1}+r b_{0}\right)^{t}\left(b_{1}+r_{I E} b_{0}\right) \rightarrow \frac{d}{d r}\left(b_{1}+r_{I E} b_{0}\right)=0 \\
b_{0}{ }^{t} b_{1}+r_{I E} \underbrace{b_{0}{ }^{t} b_{0}}_{=1}=0 \\
r_{I E}=-b_{0}{ }^{t} b_{1}
\end{gathered}
$$

Substituindo em A6:

$$
b_{I E}=\left(I-b_{0}{ }^{t} b_{0}\right) b_{1}
$$

$b_{I E}$ é a solução que traz a menor variância e, por construção, é ortogonal ao espaço nulo $b_{0}$. Para obtê-lo, utilizo a regressão por Componentes Principais (descrita a seguir).

$$
\sum_{k} \delta_{k}=\sum_{t} \gamma_{t}=\sum_{j} \varphi_{j}=0
$$

Na codificação utilizada, a soma dos coeficientes é zero. Para isso, criamos dummies para todas as idades e subtraímos a última categoria das outras: $\delta_{k}^{*}=\delta_{k}-\delta_{65}$. O mesmo é feito para período e coorte. Criamos a design matrix, $\boldsymbol{X}$ incluindo uma constante. Procedemos uma Decomposição Espectral: $\boldsymbol{X}^{\mathbf{t}} \mathbf{X}=\mathbf{S} \Delta \mathbf{S}^{\mathbf{t}}$. Excluímos a última coluna de $S$, criando a matriz $S^{*}$. Transformamos as colunas de $X$ para esse espaço: $X S^{*}=W$. Fazemos uma regressão do vetor $y$ sobre $W: a=\left(W^{t} W\right)^{-1} W^{t} y$. Para voltar ao espaço original: $\boldsymbol{b}_{I E}=S^{*} a$.

O sexto modelo foi inspirado no HAPC-CREM (Yang e Land, 2006 e 2008). Idade é tratada como efeito fixo e período e coorte como efeitos aleatórios.

$$
\begin{gathered}
\text { Modelo 6-Efeitos Mistos } \\
D_{k t}=\beta_{0}+\sum_{k} \delta_{k} I_{k}+v_{p}+v_{c}+\varepsilon_{k t} ; v_{p} \sim N(0, \tau) ; v_{c} \sim N(0, p)
\end{gathered}
$$

\section{Intervalos de confiança: Boostrapping Paramétrico}

Pelo Teorema do Limite Central: $\sqrt{n}(\hat{\beta}-\beta) \stackrel{d}{\rightarrow} N(0, \Sigma)$. Pela Lei dos Grandes Números: $N(\hat{\beta}, \hat{\Sigma}) \stackrel{P}{\rightarrow} N(\beta, \Sigma)$. Usando $\hat{\beta}$ e $\hat{\Sigma}$ (Huber-White), simulo 
5.000 vetores de coeficientes a partir de uma normal multivariada, e faço:

$$
\hat{Y}_{P \times 5000}=X_{P \times K} B_{K \times 5000}
$$

Na matriz $\hat{Y}_{P \times 5000}$, cada linha é uma distribuição de valores preditos para um perfil. O quantil 0,005 representa o limite inferior do intervalo de confiança e o quantil 0,995, o limite superior. Esses intervalos conservadores buscam contornar a impossibilidade de incorporar o plano amostral da PNAD em todos os anos (o IBGE disponibiliza essas informações apenas a partir de 1992). 


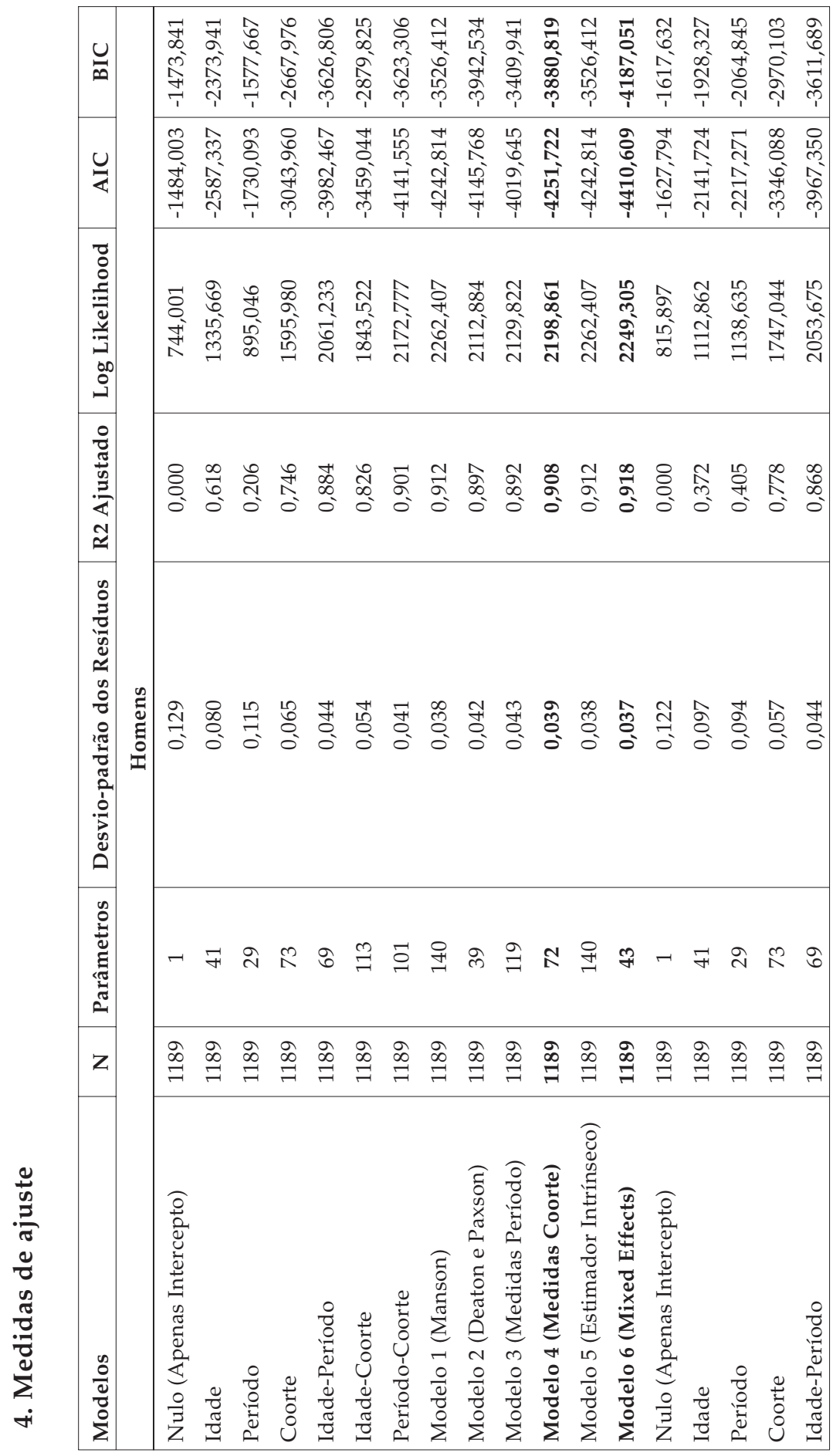


Desigualdade de Rendimentos do Trabalho no Curto e no Longo Prazo...

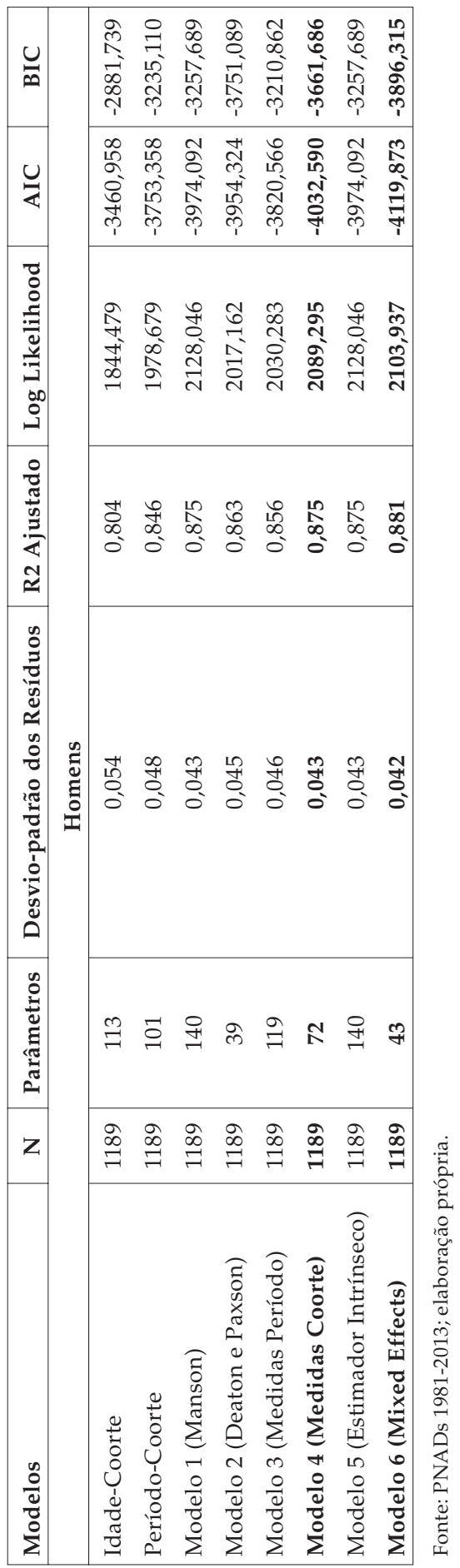

DADOS - Revista de Ciências Sociais, Rio de Janeiro, vol. 59, n 2, 2016 


\section{RESUMO}

Desigualdade de Rendimentos do Trabalho no Curto e no Longo Prazo: Tendências de Idade, Período e Coorte

Este artigo visa compreender se o movimento da desigualdade de renda do trabalho nas últimas décadas no Brasil responde mais a flutuações conjunturais ou a fatores de longo prazo. Analisa a distribuição dos rendimentos para pessoas do sexo masculino e feminino separadamente. São apresentadas as principais abordagens sobre idade, período e coorte - e delas derivam-se seis diferentes modelos para teste. Os principais achados são: 1) entre os homens, a queda das desigualdades é principalmente fruto de um processo de longo prazo, que coincide com a homogeneização educacional das coortes - os efeitos de conjunturas econômicas e medidas políticas apenas conseguiram mitigar as consequências trazidas pelas crises e instabilidades dos anos 1980;2) entre as mulheres, a queda dos indicadores se deve sobretudo a efeitos de período. Percebeu-se também que aspectos conjunturais afetam a distribuição de rendimentos de homens e mulheres de modo diferente.

Palavras-chave: desigualdade de renda; idade; período; coorte; longo prazo

\section{ABSTRACT \\ Inequality of Labor Wages in the Short and Long Run: Age, Period and Cohort Trends}

This article seeks to understand whether the shifts of income inequality in the last decades in Brazil are the result of conjuncture or long-term factors. It analyzes the distribution of income for men and women separately. The main approaches to age, period and cohort are presented and six different test models are derived from them. The main findings are: 1) among men, the decline of inequality is mainly the result of a long-term process that coincides with the educational homogenization of cohorts - the effects of economic conjunctures and political measures only mitigate the consequences of the crises and instability of the 1980s; 2) among women, the decline of the indicators is mostly due to the effects of period. It was also noted that conjuncture-related aspects affect the distribution of income of men and women differently.

Keywords: income inequality; age; period; cohort; long term 
RÉSUMÉ

Inégalité des Revenus du Travail à Court et à Long Terme: Tendances d'Âge, de Période et de Cohorte

Cet article vise à savoir si les variations de l'inégalité des revenus du travail des dernières décennies au Brésil répondent plus à des fluctuations conjoncturelles ou à des facteurs à long terme. Nous analyserons séparément la distribution des revenus chez les hommes et chez les femmes. Seront ici présentées les principales approches relatives à l'âge, à la période et à la cohorte, desquelles dérivent six différents modèles à tester. Les principaux résultats sont: 1) parmi les hommes, la chute des inégalités est principalement le fruit d'un processus à long terme qui coïncide avec l'homogénéisation éducative des cohortes - les effets de la conjoncture économique et des mesures politiques n'a réussi qu'à atténuer les conséquences des crises et des instabilités des années 1980;2) du côté des femmes, la chute des indicateurs est principalement due à des effets de période. On a pu également constater que les aspects conjoncturels affectent de manière différente la distribution des revenus des hommes et des femmes.

Mots-clés: inégalités de revenu; âge; période; cohorte; long terme

\section{RESUMEN \\ Desigualdad de Renta del Trabajo en el Corto y en el Largo Plazo: Tendencias de Edad, Período y Cohorte}

Este artículo busca comprender si el movimiento de la desigualdad de renta del trabajo en las últimas décadas en Brasil responde a fluctuaciones coyunturales o a factores de largo plazo. La distribución de rendimientos para las personas del sexo masculino y femenino son analizadas separadamente. Tras presentar los principales enfoques sobre edad, período y cohorte, se eligen seis diferentes modelos para validación. Los principales hallazgos son: 1) entre los hombres, la disminución de las desigualdades es, ante todo, fruto de un proceso de largo plazo, que coincide con la homogeneización educativa de las cohortes - los efectos de las coyunturas económicas y medidas políticas apenas lograron mitigar las consecuencias de las crisis e inestabilidades de los años 1980; 2) entre las mujeres, la caída de los indicadores se debe, sobre todo, a efectos de período. Igualmente, se pudo constatar que aspectos coyunturales afectan la distribución de rendimientos de hombres y mujeres de manera diferenciada.

Palabras clave: desigualdad de renta; edad; período; cohorte; largo plazo 